\title{
Inductive Textile Sensor Design and Validation for a Wearable Monitoring Device
}

\author{
Astrid García Patiño and Carlo Menon *D \\ Menrva Research Group, Schools of Mechatronic Systems \& Engineering Science, Simon Fraser University, \\ Metro Vancouver, BC V5A 1S6, Canada; agarciap@sfu.ca \\ * Correspondence: cmenon@sfu.ca
}

Citation: Patiño, A.G.; Menon, C. Inductive Textile Sensor Design and Validation for a Wearable Monitoring Device. Sensors 2021, 21, 225. https://doi.org/10.3390/s21010225

Received: 4 December 2020 Accepted: 28 December 2020 Published: 1 January 2021

Publisher's Note: MDPI stays neutral with regard to jurisdictional clai$\mathrm{ms}$ in published maps and institutional affiliations.

Copyright: (C) 2021 by the authors. Licensee MDPI, Basel, Switzerland. This article is an open access article distributed under the terms and conditions of the Creative Commons Attribution (CC BY) license (https:// creativecommons.org/licenses/by/ $4.0 /)$.

\begin{abstract}
Textile sensors have gained attention for wearable devices, in which the most popular are the resistive textile sensor. However, these sensors present high hysteresis and a drift when stretched for long periods of time. Inductive textile sensors have been commonly used as antennas and plethysmographs, and their applications have been extended to measure heartbeat, wireless data transmission, and motion and gesture capturing systems. Inductive textile sensors have shown high reliability, stable readings, low production cost, and an easy manufacturing process. This paper presents the design and validation of an inductive strain textile sensor. The anthropometric dimensions of a healthy participant were used to define the maximum dimensions of the inductive textile sensor. The design of the inductive sensor was studied through theoretical calculations and simulations. Parameters such as height, width, area, perimeter, and number of complete loops were considered to calculate and evaluate the inductance value.
\end{abstract}

Keywords: inductance; textile sensors; wearable device; smart garment; E-textiles

\section{Introduction}

Electronic textiles, also known as E-textiles or smart garments, could be a solution for monitoring daily activities due to their small size, light weight, and simple operation [1,2]. As a result, they can comfortably be worn by participants without obstructing their daily activities.

Inductive textile sensors are made from highly conductive materials (e.g., copper wire, stainless steel yarn, conductive threads). These sensors base their working principle on their capacity to create a magnetic field when an electrical current is passed through loop(s) of the conductive threads [3]. The sensor's output is modified when the shape of the magnetic field changes. These changes are the result of deforming the sensor due to an externally applied force. Fava et al. [4] reported that the inductance and the sensitivity ( $\Delta$ Inductance/ $\Delta$ strain) of the sensor can be increased by augmenting the number of coils and/or narrowing the width and space between the coils [4]. Typically, inductive sensors are manufactured with a circular coil shape, however, they are not limited to only this shape [5]. The versatility of the inductive textile sensors enables the ability to embed or affixed these sensors to different surfaces. Inductive sensors are regularly used in antennas [6,7] and plethysmographs [5,6,8].

Yoo [9] and Coosemans et al. [10] used inductive-type sensors for wireless-powered applications. Coosemans et al. [10] created a platform using these types of sensors to transmit ECG measurement data. To measure the heartbeat, Koo et al. [11] developed a magnetic-induced conductivity sensing module shaped in a coil configuration using nine strands of silver-polyester hybrid yarn. Wijesiriwardana [12] manufactured a knitted sensor made with Lycra and copper wire to measure strain and displacement, suggesting the possibility of expanding the sensor's applications to respiratory measuring and motion and gesture capturing systems. This sensor was reported to be ideal for wearable devices given its unobtrusive behavior, small size, lightweight, comfort, and tightfitting properties. Wu 
et al. [13] presented a wearable inductive plethysmography to monitor respiration during sleep. This inductive plethysmography showed high reliability and low production cost.

Commonly, monitoring E-textile devices are based on resistive sensors. However, resistive sensors present important disadvantages that limit their practicality, such as high hysteresis, non-linearity of their response, and a drift in their readings when a certain amount of stretch is held for a period of time [2]. The aforementioned disadvantages can be overcome through the use of inductive textile sensors since these sensors do not present a drift in their output signal over time, which makes them a reliable monitoring system for an extended period of time. Additionally, inductive textile sensors' output signals present minimal noise, almost linear behavior, almost no hysteresis, straightforward signal processing, and do not require specialized equipment or materials $[2,14,15]$. Unfortunately, there is little information regarding the design and manufacture of the inductive textile sensors.

In this study, the process for designing an inductive strain textile sensor with a flat rectangular coil configuration is proposed. The inductance value behavior was studied based on the change of its dimensions and number of complete loops. A series of simulations were performed to validate the theoretical calculations and evaluate the inductance behavior when variables such as the material of the sensor and its surrounding was considered. Finally, the design process was applied to design and develop an inductive textile sensor to monitor the trunk forward bending [3].

\section{Design Process}

In this study, we investigated the design and validation of an inductive strain textile sensor. The design of the sensor started by defining its size. Then, the inductance value of the sensor was theoretically calculated using equations from the literature to understand the behavior of the inductance when a change in the geometry of the sensor occurred. This was followed by a comparison between different theoretical calculations based on perimeter/area and height/width of a single loop rectangle. Additionally, theoretical calculations based on the number of complete loops of a flat rectangular coil were investigated. Next, a series of simulations were investigated to verify the values obtained from theoretical calculation and the impact of including variables such as the material of the sensor and its surrounding environment. Figure 1 illustrates the design process for the inductive strain textile sensor.

\subsection{Defining Maximum Size}

The goal of this step was to numerically identify the total size where the sensor was going to be placed. In the case of wearable textile sensors, its size can be defined by the anthropometry. Anthropometry is the human science that studies body measurements such as body size, shape, strength, and working capacity [16]. Investigation into the anthropometrics of the target region is recommended.

\subsection{Theoretical Calculation of the Inductance Value for a Flat Rectangular Coil Sensor}

Two approaches for the designing of the sensor were considered: First, the calculation of a simple rectangle based on its dimensions, such as height, width, perimeter, and area [17-19], and second, the calculation of a flat rectangle coil using the Terman equation was performed [18]. In both approaches, the inductance behavior was analyzed when the height, width, perimeter, area, or number of loops were modified. 


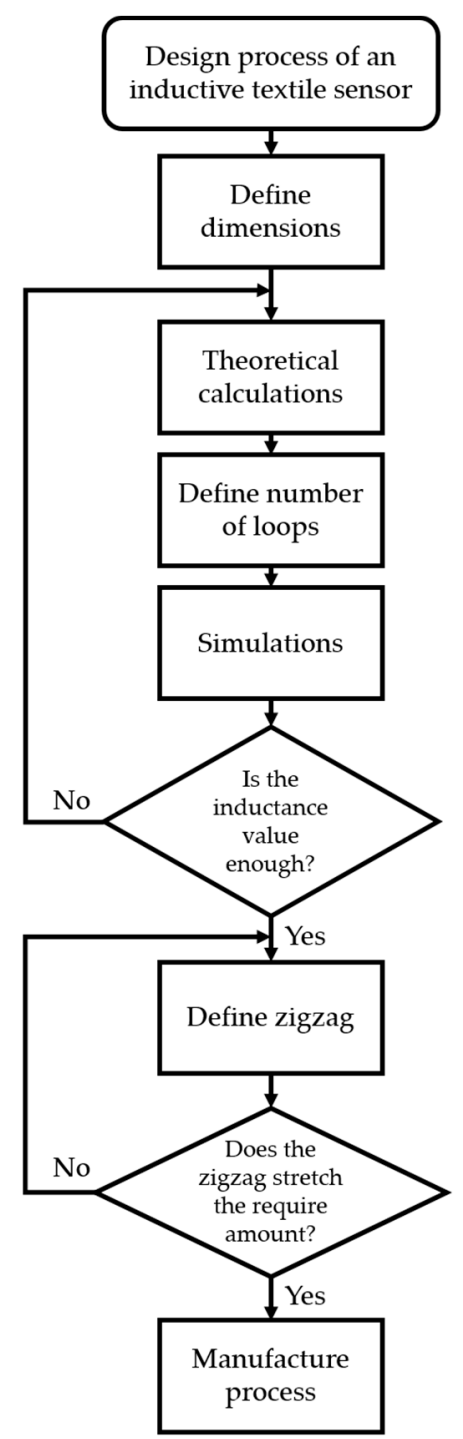

Figure 1. Diagram for the design process of an inductive strain textile sensor with a flat rectangular coil configuration.

\subsubsection{Inductance of a Rectangle with Round Wire}

Thompson [17] and Grover [19] presented several equations to calculate the inductance based on the shape of an antenna and the type of wire used. The two equations used to calculate the inductance of a rectangle are $[17,19]$ :

$$
\begin{gathered}
L \simeq \frac{\mu_{0} p}{2 \pi}\left[\ln \left(\frac{2 p}{R}\right)+0.25-\ln \left(\frac{p^{2}}{a}\right)\right] \\
L \simeq \frac{\mu_{0} \mu_{r}}{\pi}\left[-2\left(W \quad \begin{array}{r}
+H)+2 \sqrt{H^{2}+W^{2}}-H \ln \left(\frac{H+\sqrt{H^{2}+W^{2}}}{W}\right) \\
\left.-W \ln \left(\frac{W+\sqrt{H^{2}+W^{2}}}{H}\right)+H \ln \left(\frac{2 H}{R}\right)+W \ln \left(\frac{2 W}{R}\right)\right]
\end{array}\right.\right.
\end{gathered}
$$

where $\mu_{0}$ is the magnetic permeability of free space equal to $4 \Pi \times 10^{-7} \mathrm{H} / \mathrm{m}$, and $\mu_{\mathrm{r}}$ is the relative permeability of the material inside the rectangle loop. The variable $\mu_{\mathrm{r}}$ is considered to be air, the value of which is 1 . The perimeter of the polygon is $p$, the area of the polygon is $a$, the width of the rectangle is $W$, the height of the rectangle is $H$, and finally, the radius of the wire is $R$. 
Equation (1) calculates the inductance of a polygon, with any perimeter and area, composed of a round wire. Figure 2 shows the inductance behavior based on Equation (1). From Figure 2, it was noticeable that the inductance increased with an almost linear behavior when the area was kept constant and the perimeter increases.

a.

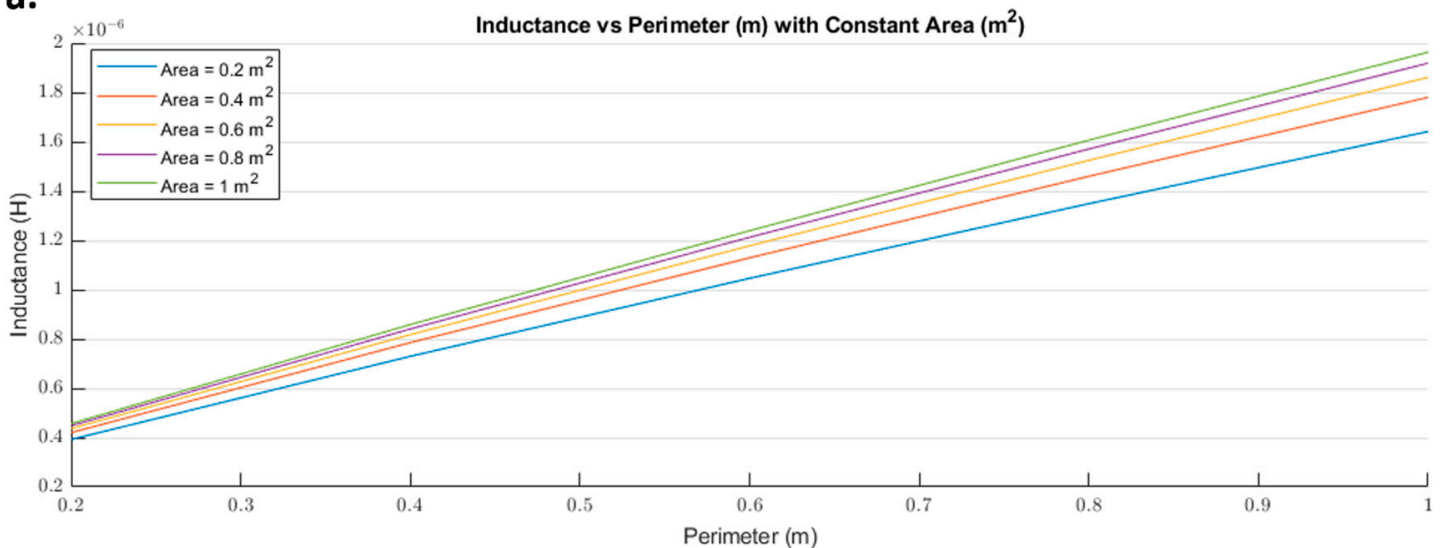

b.

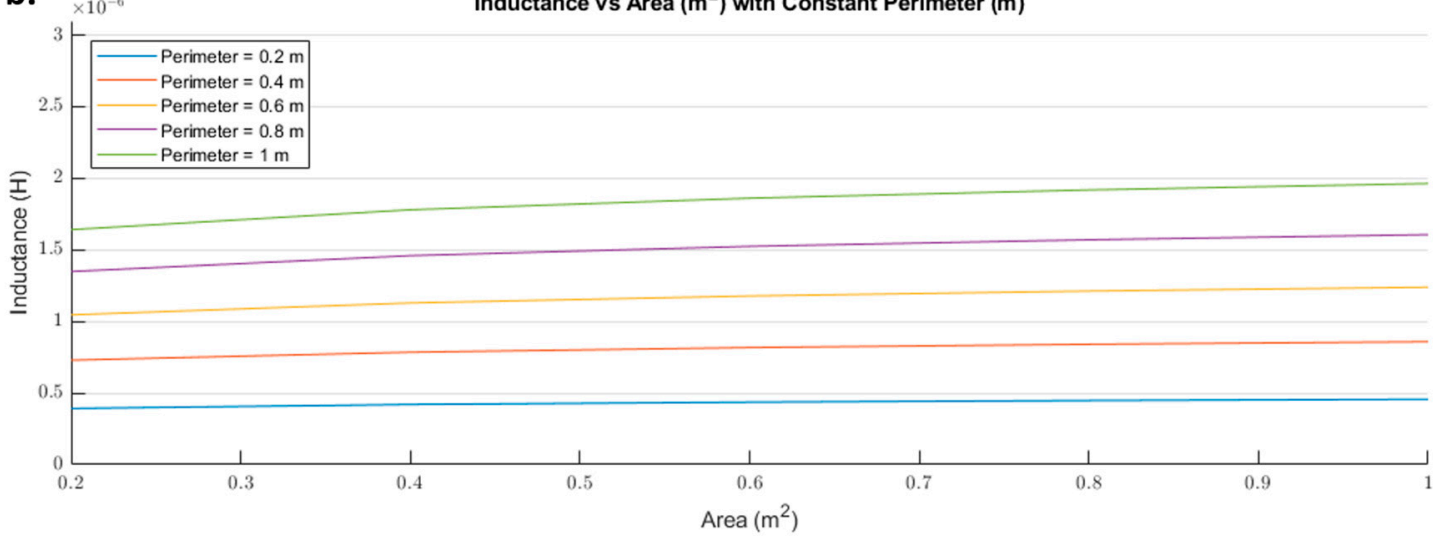

Figure 2. Inductance $(\mathrm{H})$ behavior based on the area $\left(\mathrm{m}^{2}\right)$ and perimeter $(\mathrm{m})$ of a polygon using a round wire: (a) Inductance value vs. perimeter with a constant area; (b) inductance vs. area with a constant perimeter.

Equation (2) calculates the inductance value according to the height and width of the rectangle loop. Figure 3 illustrates the behavior of Equation (2), where both height and width are in meters and the inductance is in henries. From Figure 3, we observed that the inductance rapidly increased with a linear behavior when the height was kept constant and the width increased. Equation (2) shows a linear behavior regardless of the variable kept constant. The inductance value will rapidly decrease when either the width or the height is closer to zero due to the natural logarithms in Equation (2). Additionally, both equations neglected the loop's material, but did consider the radius of the wire. 


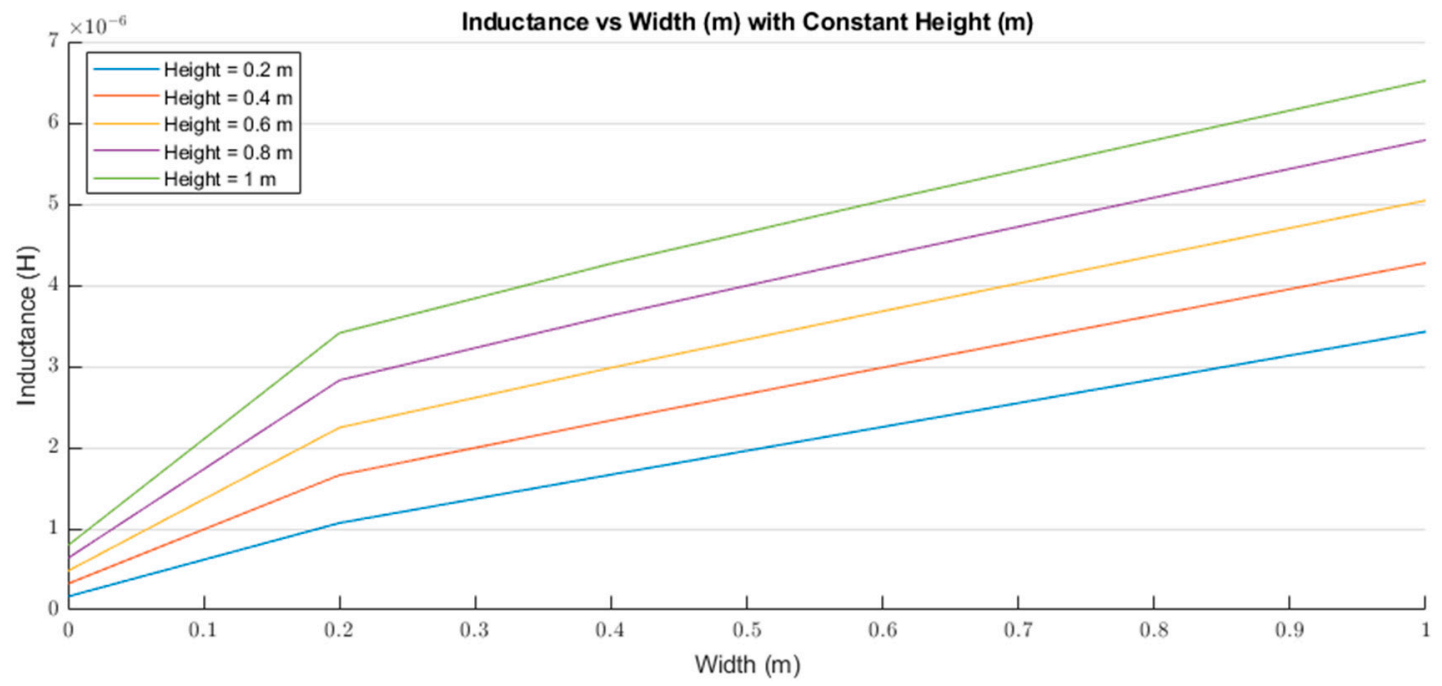

Figure 3. Inductance $(\mathrm{H})$ behavior based on the height $(\mathrm{m})$ and width $(\mathrm{m})$ of a rectangle loop.

\subsubsection{Flat Rectangular Coil}

Terman [18] developed Equation (3) to calculate the low-frequency inductance of a flat rectangular coil. This equation depends on the average dimensions of the rectangle and the number of complete turns of the wire [18]:

$$
\begin{gathered}
L \simeq 0.02339 n^{2} \quad\left[\left(s_{1}+s_{2}\right) \log _{10} \frac{2 s_{1} s_{2}}{n D}-s_{1} \log _{10}\left(s_{1}+g\right)-s_{2} \log _{10}\left(s_{2}+g\right)\right] \\
+0.01016 n^{2}\left(2 g-\frac{s_{1}+s_{2}}{2}+0.447 n D\right) \\
-0.01016 n\left(s_{1}+s_{2}\right)(A+B)
\end{gathered}
$$

where $s_{1}$ and $s_{2}$ are the average dimensions of the rectangle, $g$ is the average diagonal $g=\sqrt{s_{1}^{2}+s_{2}^{2}}, n$ is the number of complete turns with a pitch of winding $D$. Figure 4 illustrates the flat rectangular coil configuration.

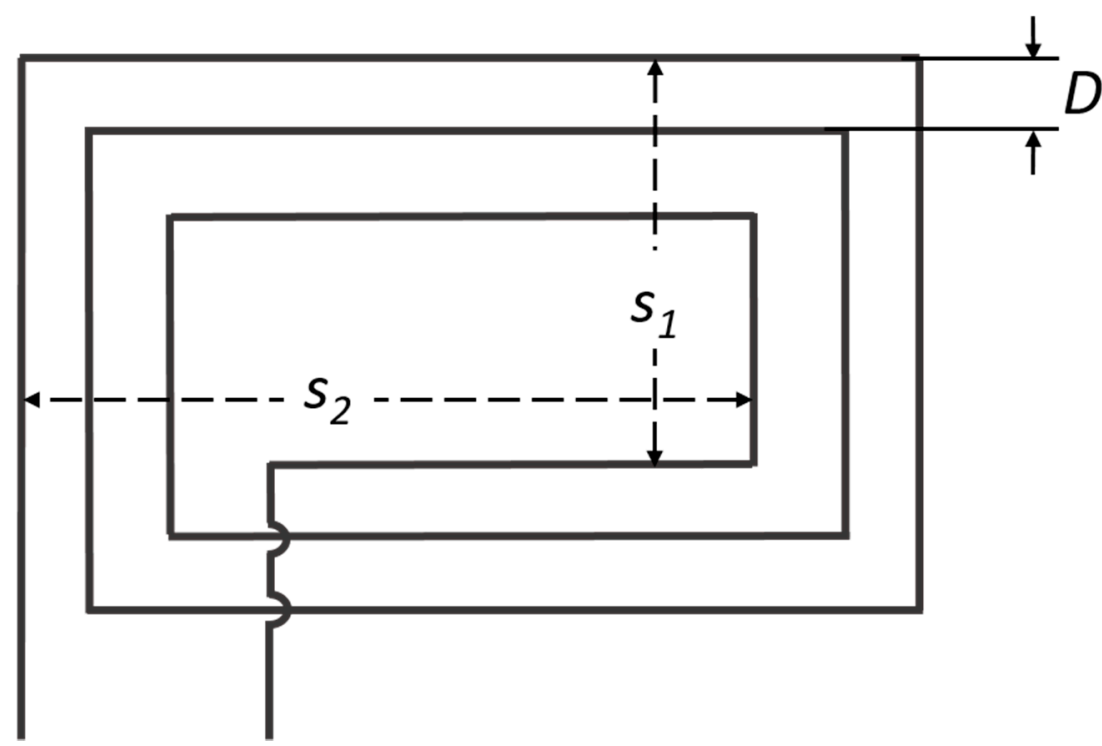

Figure 4. Flat rectangle coil geometry presented by Terman. Adapted from [18].

Furthermore, $A$ and $B$ are correction constants based on the wire spacing and the number of turns, respectively. Table 1 shows the correction constants for $A$ from 0.01 to 0.1 , and Table 2 shows the $B$ correction constants from 1 to 10 . Complete tables for correction 
constants $A$ and $B$ are found in the Radio Engineers' Handbook by Terman [18]. Terman used the English system for calculations in Equation (3), therefore, the dimensions are in inches.

Table 1. Correction values of constant $A$ in Equation (3) from 0.01 to 0.1 .

\begin{tabular}{cc}
\hline Wire Diameter/D & $A$ \\
\hline 0.01 & -4.048 \\
0.02 & -3.355 \\
0.03 & -2.950 \\
0.04 & -2.662 \\
0.05 & -2.439 \\
0.06 & -2.256 \\
0.07 & -2.102 \\
0.08 & -1.969 \\
0.09 & -1.851 \\
0.1 & -1.746 \\
\hline
\end{tabular}

Table 2. Correction values of constant $B$ in Equation (3) from 1 to 10.

\begin{tabular}{cc}
\hline Number of Turns $(\boldsymbol{n})$ & $\boldsymbol{B}$ \\
\hline 1 & 0.000 \\
2 & 0.114 \\
3 & 0.166 \\
4 & 0.197 \\
5 & 0.218 \\
6 & 0.233 \\
7 & 0.244 \\
8 & 0.253 \\
9 & 0.260 \\
10 & 0.266 \\
\hline
\end{tabular}

Equations (1)-(3) do not consider the material of the sensor. Moreover, the diameter of the wire is only considered in the correction constant $A$. The geometry and symmetry of the sensor in Equation (3) are extremely important given that average dimensions $\left(s_{1}, s_{2}\right.$, and $g$ ), as well as the distance between loops $\mathrm{D}$, are considered. Therefore, a slight modification in the geometry of the sensor during the manufacturing process can have a great impact on the inductance value.

\subsection{Simulations}

In this study, all the simulations were performed in Ansys 2019 R2/19.4 Electromagnetics (Ansys Inc., Canonsburg, PA, USA) using Maxwell 3D design. The objective of the simulations was to validate the theoretical calculations and evaluate the change of inductance value when variables such as the material of the sensor differed.

Previous studies used copper, silver, and stainless steel to manufacture inductive textile sensors for diverse applications $[8,10-12,20,21]$. We performed a series of simulations to evaluate the change of the inductance value when different materials were used for a single loop sensor. Table 3 shows the parameters used in the Ansys for the comparison of materials for the same inductive sensor. Figure 5 illustrates the characteristics of the simulated sensor used for this section. Finally, Figure 6 illustrates the comparison on the inductance value of a simulated inductive sensor using different materials such as copper, silver, gold, and stainless steel. 
Table 3. Ansys parameters used for simulating inductance value for different materials.

\begin{tabular}{ccc}
\hline & Ansys' Parameters & Sensor \\
\hline & Between Connections & $10 \mathrm{~mm}$ \\
Sensor's & Total Height & $60 \mathrm{~mm}$ \\
Characteristics & Total Length & $50 \mathrm{~mm}$ \\
& Material & Copper, Silver, Gold, Stainless steel \\
& Wire Diameter & $0.14 \mathrm{~mm}$ \\
\hline \multirow{3}{*}{ Box } & X & $150 \mathrm{~mm}$ \\
Characteristics & Y & $120 \mathrm{~mm}$ \\
& Material & $100 \mathrm{~mm}$ \\
& \% Error & Air \\
\hline Setup & Maximum \# Passes & 10 \\
& Minimum \# of Passes & 1 \\
& Minimum Converged Passes & 30 \\
& & 5 \\
\end{tabular}

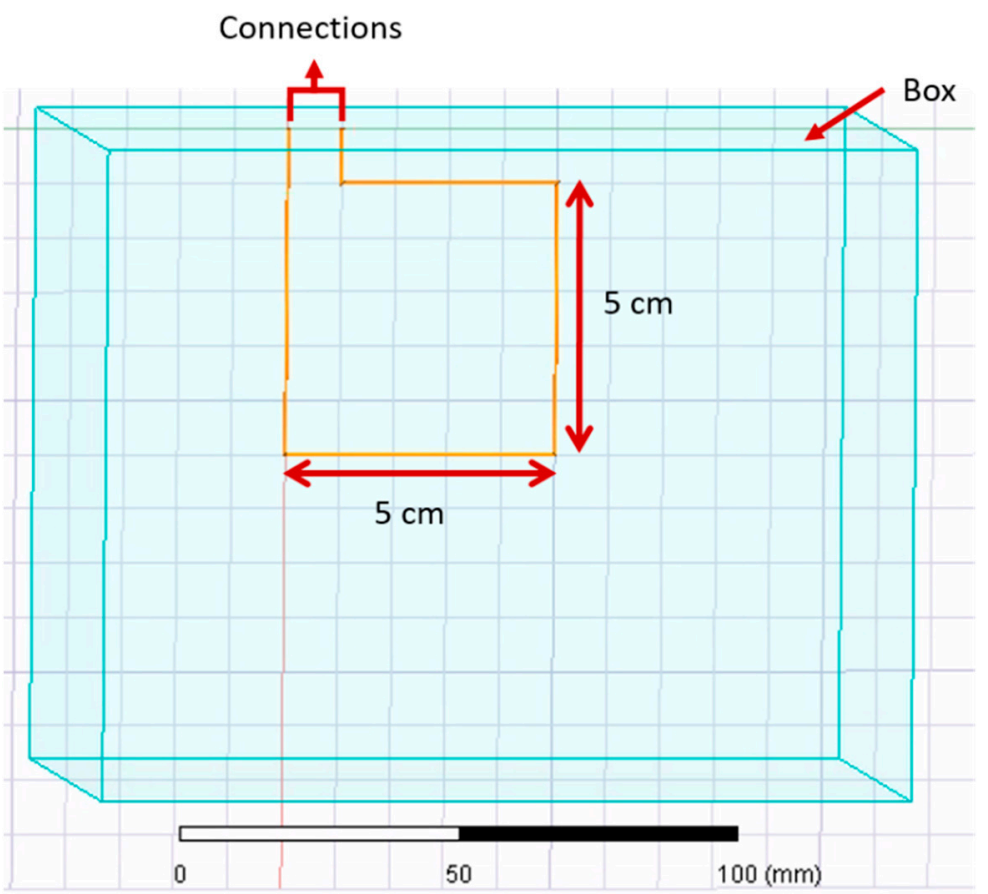

Figure 5. The sensor's characteristics used to compare the simulated inductance value of different materials.

In Table 3, "Sensor's Characteristics" describes the properties used for this comparison. The parameter "Box" describes the dimensions and material surrounding the inductive sensor (light blue).

The total change range of the inductance value obtained from using different materials was $0.424 \mathrm{pH}$. The material that obtained the higher inductance value was stainless steel with an inductance value of $251.1761 \mathrm{nH}$, followed by copper with an inductance value of $251.1760 \mathrm{nH}$. The inductance difference between both materials was $0.095 \mathrm{pH}$. The material that had the lowest inductance value was gold with an inductance value of $251.1756 \mathrm{nH}$. The effect of the material on the inductance value can be neglectable when the working range of the inductive sensor is in $\mathrm{nH}$ or higher. 


\section{Comparison of Inductance Value and Material}

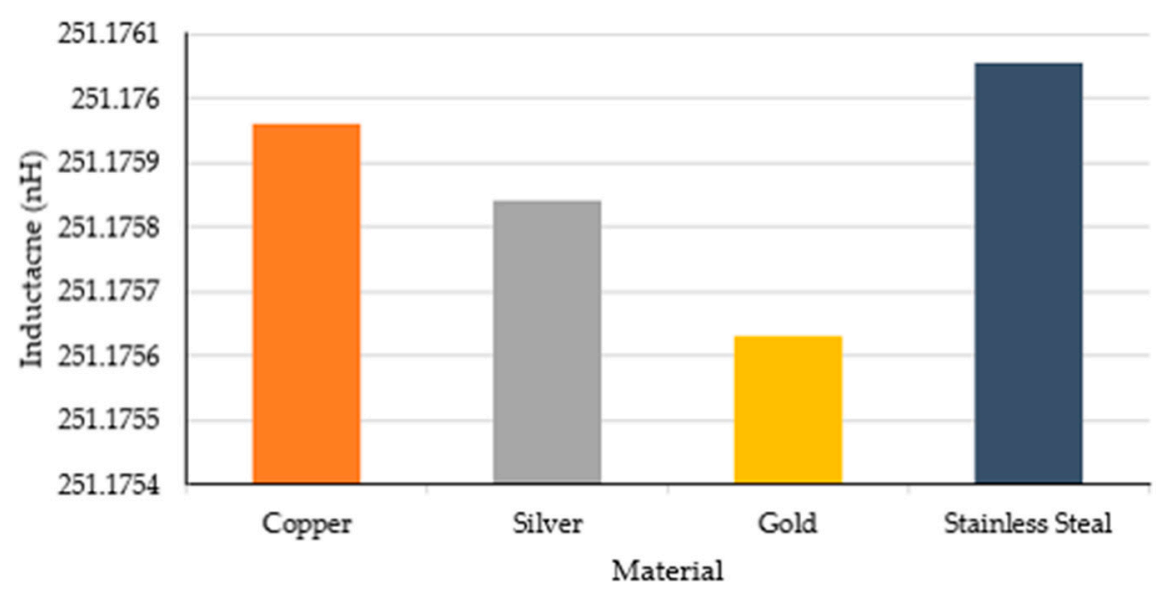

Figure 6. Comparison of simulated inductance value of the same sensor using copper, silver, gold, and stainless steel.

\subsection{Zigzag Properties}

The zigzag pattern used in the design of the inductive sensor is a property that provided an increase of inductance of $35 \%$ when compared with a straight line [3]. Furthermore, the zigzag pattern allowed the sensor to be stretched without damaging it. In a previous study [3], we presented data that showed the width of the zigzag pattern had an effect on the inductance value. The inductance value increased when the width of the zigzag pattern was reduced. Moreover, zigzag widths of 2 and $4 \mathrm{~mm}$ were able to be stretched up to $200 \%$ of their original length.

\subsection{Manufacture Process}

The integration of inductive textile sensors into a garment or fabric can be done by sewing or knitting [3,8,10-12,14,20-22].

The sewing technique allows for the integration of textile sensors into the fabric during the manufacturing process. This advantage provides the possibility of selecting the best stitch for each type of fabric $[23,24]$. Some popular stitches used for stretchable fabrics are zigzag, curve, wave, and sinusoidal pattern. Sewing textile sensors into the fabric or garment presents several advantages such as geometry versatility, manufacturing ease, and the ability to replace the sensor without damaging the garment or fabric.

Using the knitting technique, textile sensors are created with a flat-bed knitting machine using either interlocking or plain knitted structures. These sensors have the advantage of conforming to the shape of the body, as well as improved elasticity and breathability $[22,23]$. This technique can be done with a variety of conductive yarns, such as copper, silver-coated nylon yarns, polyester-blended yarn with stainless steel fibers, and double covered elastomeric yarns $[6,12,22,23,25]$.

\section{Example Case}

In this section, we present an example cause of an inductive strain textile sensor created following the presented methodology (Figure 1). The textile sensor was made by sewing a single copper wire with a diameter of $0.14 \mathrm{~mm}$ into a piece of elastic fabric. The wire diameter was selected based on its close similarity to the diameter of common thread and its possibility to be attached to the fabric using a sewing machine. Furthermore, the inductance value of the textile sensor increases with a smaller wire diameter. The detailed manufacture and performance of the aforementioned sensor was presented in [3]. Figure 7 illustrates the manufactured inductive sensor and the final prototype being worn by a participant. 
a.
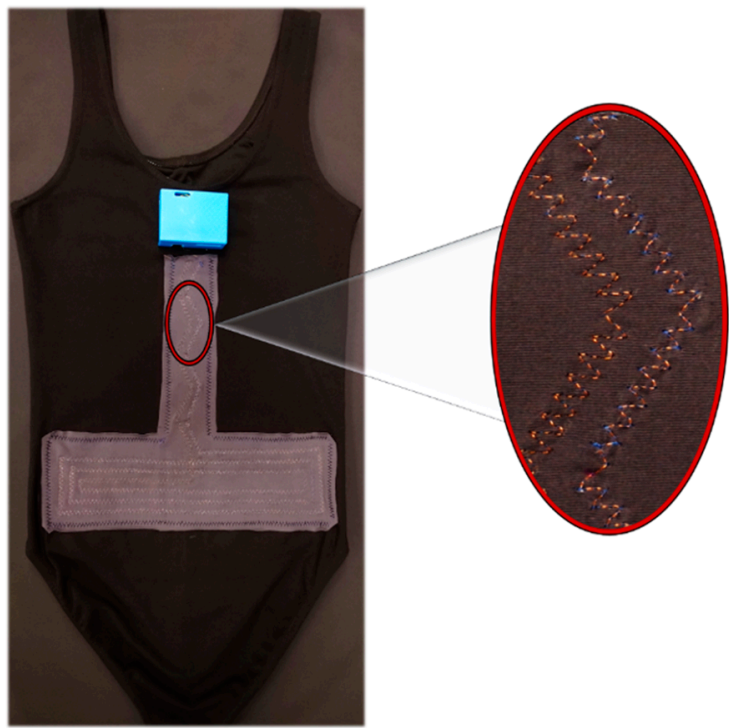

b.

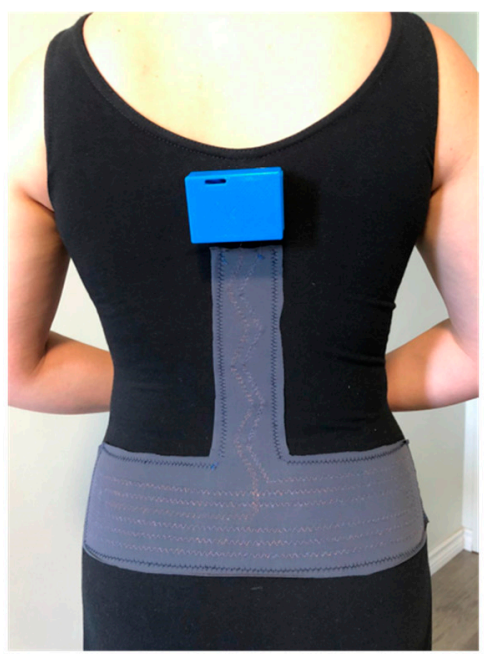

c.

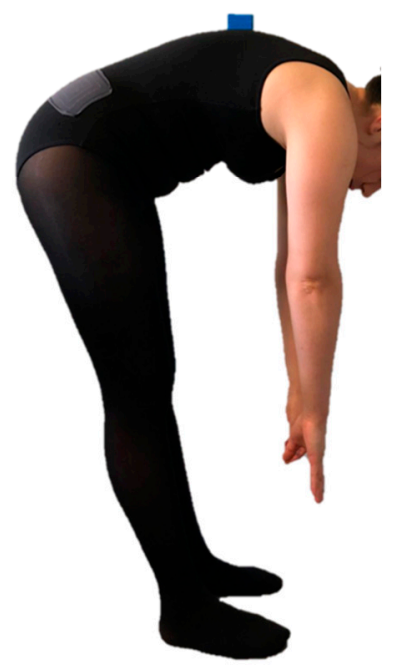

Figure 7. Smart garment: (a) Inductive strain textile sensor attached to a leotard [3]; (b) rear view of the smart garment worn by a participant; (c) participant performing forward bending while wearing the smart garment.

\subsection{Anthropometry}

The objective of the sensor as designed was to detect forward bending of the trunk while rejecting other movements, such as lateral bending or twisting [3]. To achieve this goal, the configuration and placement of the sensor was chosen strategically. Previous studies reported that when an individual wearing a tight-fitting shirt bends forward, the lumbar section of the back undergoes major strain [26]. The trunk movements in the frontal and horizontal planes, which correspond to lateral bending and rotation, cause a smaller strain on this section [26]. According to this evidence, the inductive strain textile sensor was positioned on the lumbar area, using a flat rectangle coil shape.

Given that more than $90 \%$ of nurses are female [27-29], the anthropometry of a healthy female was used as the reference in designing and testing the inductive strain textile sensor developed in this study.

The trunk's general anthropometry dimensions of a healthy female using a 95th percentile [30] and anthropometrics measurements gathered by previous studies [31-33] was employed in the design of the sensor. The collected measurements are summarized in Table 4 and illustrated in Figure 8. 
Table 4. Anthropometry dimensions of a healthy female of 25-40 years old.

\begin{tabular}{cc}
\hline \multicolumn{2}{c}{ Trunk's Anthropometry } \\
\hline Trunk width at the iliac crest & $28 \mathrm{~cm}$ \\
Trunk length C7-L5 & 41.7 to $42.5 \mathrm{~cm}$ \\
Waist height & $103.4 \mathrm{~cm}$ \\
Trochanteric height & $82.4 \mathrm{~cm}$ \\
\hline
\end{tabular}

a.

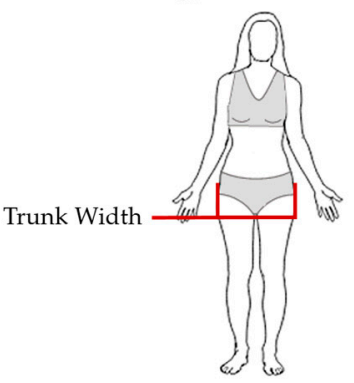

b.

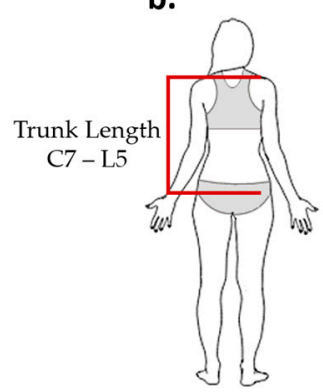

c.

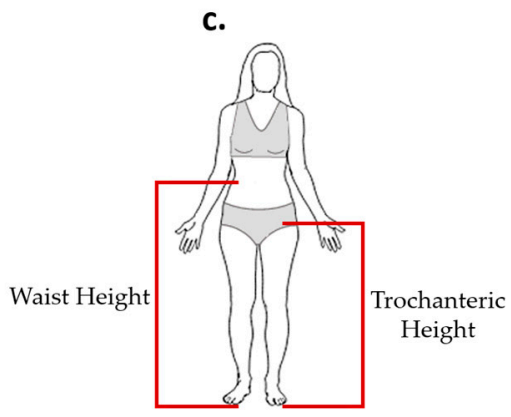

Figure 8. Anthropometric dimensions. (a) Trunk width at the iliac wrest [32], (b) trunk length from C7 to L5 [31], (c) waist height and trochanteric height [30]. Adapted from [34].

Podbevsêk [33] reported the distance between the waist and hip to be approximately $20 \mathrm{~cm}$. On the other hand, the National Aeronautics and Space Administration (NASA) Anthropometry Source Book [30] reported that the distance between the trochanteric height and waist height was approximately $21 \mathrm{~cm}$ (shown in Table 1). Given these measurements, the total height from L1 to S5 was approximated to be $20 \mathrm{~cm}$ for a healthy female of 21-40 years old. We excluded the sacrum area of the back to maintain the comfortability by reducing the area covered by the inductive sensor. Additionally, reducing the placement area of the sensor from L1-S5 to L1-L5 provided a flatter surface, which also avoided the introduction of wrinkles. Figure 9 shows the maximum dimensions of the sensor. These dimensions were used as a reference when designing and evaluating the inductive sensor through theoretical calculations and simulations.

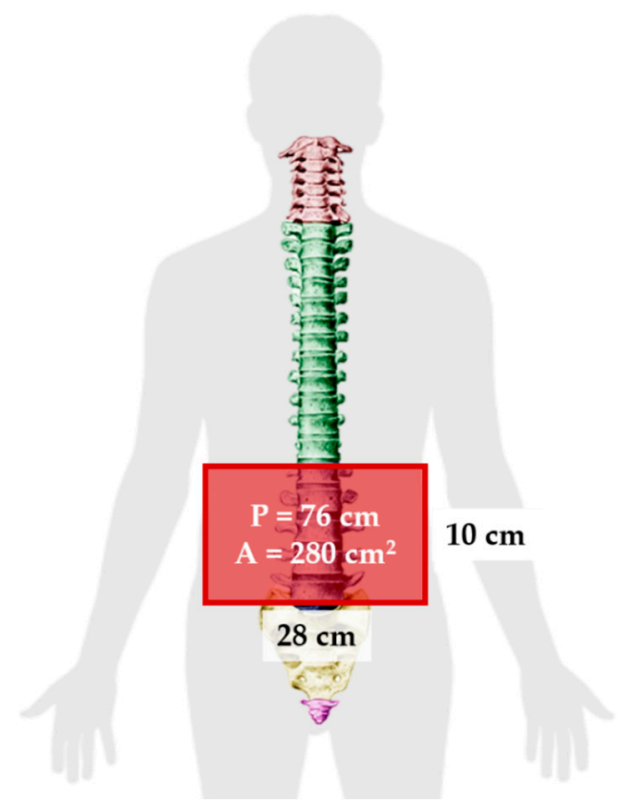

Figure 9. Maximum dimensions for the inductive sensor design. $\mathrm{P}$ and $\mathrm{A}$ represent the perimeter and the area, respectively. This image is licensed under a Creative Commons Attribution-Share Alike license (CC BY-SA) [35,36]. 


\subsection{Simulating Inductance Value of a Rectangle Using Ansys}

A series of simulations were performed in Ansys 2019 R2/19.4 Electromagnetics (Ansys Inc., Canonsburg, PA, USA) using Ansys Maxwell 3D design. Table 5 shows the parameters used in the Ansys simulations for this section. Figure 10 illustrates the characteristics of the single loop rectangle used for simulations in Sections 3.2.1 and 3.2.2.

Table 5. Parameters used for simulating inductance value using Ansys.

\begin{tabular}{ccc}
\hline \multicolumn{2}{c}{ Ansys' Parameters } & Sensor \\
\hline \multirow{2}{*}{ Sensor's Characteristics } & Material & Copper \\
& Wire Diameter & $0.14 \mathrm{~mm}$ \\
\hline \multirow{3}{*}{ Box Characteristics } & $\mathrm{Y}$ & $600 \mathrm{~mm}$ \\
& $\mathrm{Z}$ & $150 \mathrm{~mm}$ \\
& Material & $100 \mathrm{~mm}$ \\
& Maximum \# Passes & Air \\
\hline \multirow{2}{*}{ Setup } & \% Error & 10 \\
& \% Refinement Per Pass & 1 \\
& Minimum \# of Passes & 30 \\
Mesh & Minimum Converged Passes & 5 \\
\hline Excitation & Classic, Small & 1 \\
\hline
\end{tabular}

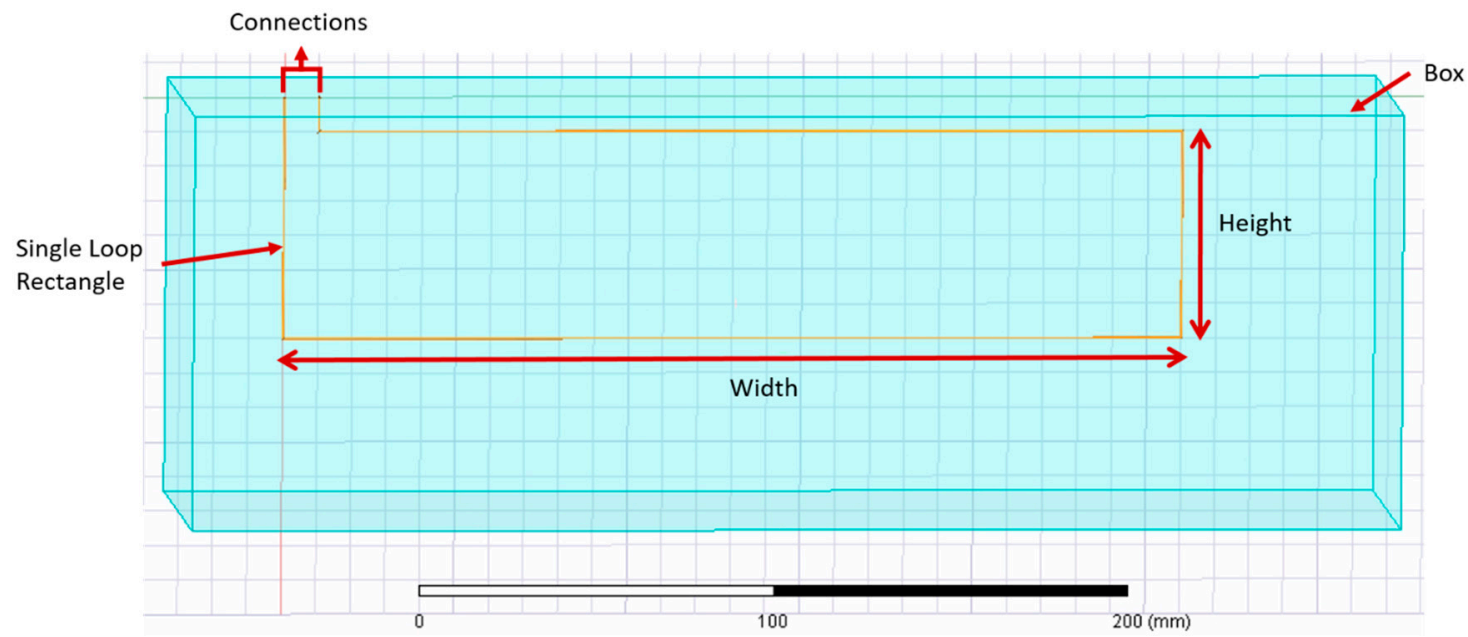

Figure 10. Single loop rectangle simulated in Ansys for Sections 3.1 and 3.2.

In Table 5, "Sensor's Characteristics" describes the properties used in this study for all the simulations performed in Ansys. Moreover, Ansys Maxwell 3D required delimitation of the space, denoted by "Box" in Table 5, and to specify the material of the object, which in this case was air.

\subsubsection{Inductance Change Based on Perimeter and Area}

This section explores the effect of changing the perimeter and area of a single loop rectangular sensor on the inductance value. The performed simulations were divided into two sets, keeping the area constant in one set and keeping the perimeter constant in the other one. Tables 6 and 7 show the specifications of the first and second set of simulations, respectively. 
Table 6. Single loop rectangle dimensions with a constant area $\left(15,600 \mathrm{~mm}^{2}\right)$.

\begin{tabular}{ccc}
\hline Perimeter $(\mathbf{m m})$ & Width $(\mathbf{m m})$ & Height $(\mathbf{m m})$ \\
\hline 556 & 200 & 78 \\
581.82 & 220 & 70.91 \\
610 & 240 & 65 \\
640 & 260 & 60 \\
671.42 & 280 & 55.71 \\
704 & 300 & 52 \\
737.5 & 320 & 48.75 \\
\hline
\end{tabular}

Table 7. Single loop rectangle dimensions with a constant perimeter $(640 \mathrm{~mm})$.

\begin{tabular}{ccc}
\hline Area $\left(\mathbf{m m}^{\mathbf{2}}\right)$ & Width $(\mathbf{m m})$ & Height $(\mathbf{m m})$ \\
\hline 3100 & 310 & 10 \\
6000 & 300 & 20 \\
11,200 & 280 & 40 \\
15,600 & 260 & 60 \\
19,200 & 240 & 80 \\
22,000 & 220 & 100 \\
24,000 & 200 & 120 \\
25,200 & 180 & 140 \\
25,600 & 160 & 160 \\
\hline
\end{tabular}

\subsubsection{Inductance Change Based on Height and Width}

This section investigates the variations in the inductance of a single loop rectangle with changing the height and width. Similar to the previous section, simulations were divided into two sets, each maintaining either a constant height or a constant width for the single loop rectangle. Table 8 shows the specifications of the first and second sets of simulations.

Table 8. Single loop rectangle dimensions with keeping either height or width constant.

\begin{tabular}{cc}
\hline Constant Height $(\mathbf{6 0} \mathbf{~ m m})$ & Constant Width $\mathbf{2 6 0} \mathbf{~ m m})$ \\
\hline Width $(\mathbf{m m})$ & Height $(\mathbf{m m})$ \\
\hline 230 & 30 \\
240 & 40 \\
250 & 50 \\
260 & 60 \\
270 & 70 \\
280 & 80 \\
290 & 90 \\
\hline
\end{tabular}

3.2.3. Inductance Change Based on the Number of Loops in a Flat Rectangular Coil

The relationship between the inductance value and the number of loops in a flat rectangular coil was also investigated. The distance between each loop $D$ was arbitrarily set to $10 \mathrm{~mm}$. Figure 11 illustrates an example of the flat rectangular coil simulated in Ansys.

\subsection{Results}

This section compares the results obtained from theoretical calculations in Section 2.2 and simulations in Section 3.2. The data of both sections were processed using MATLAB R2018b (The MathWorks, Inc., Natick, MA, USA). 
3.3.1. Comparison between Calculations and Simulations: Inductance Change Based on Perimeter and Area

Tables 9 and 10 show the results of the calculated inductance from simulations. In Table 9, the area was kept constant, while in Table 10 the constant parameter was the perimeter.

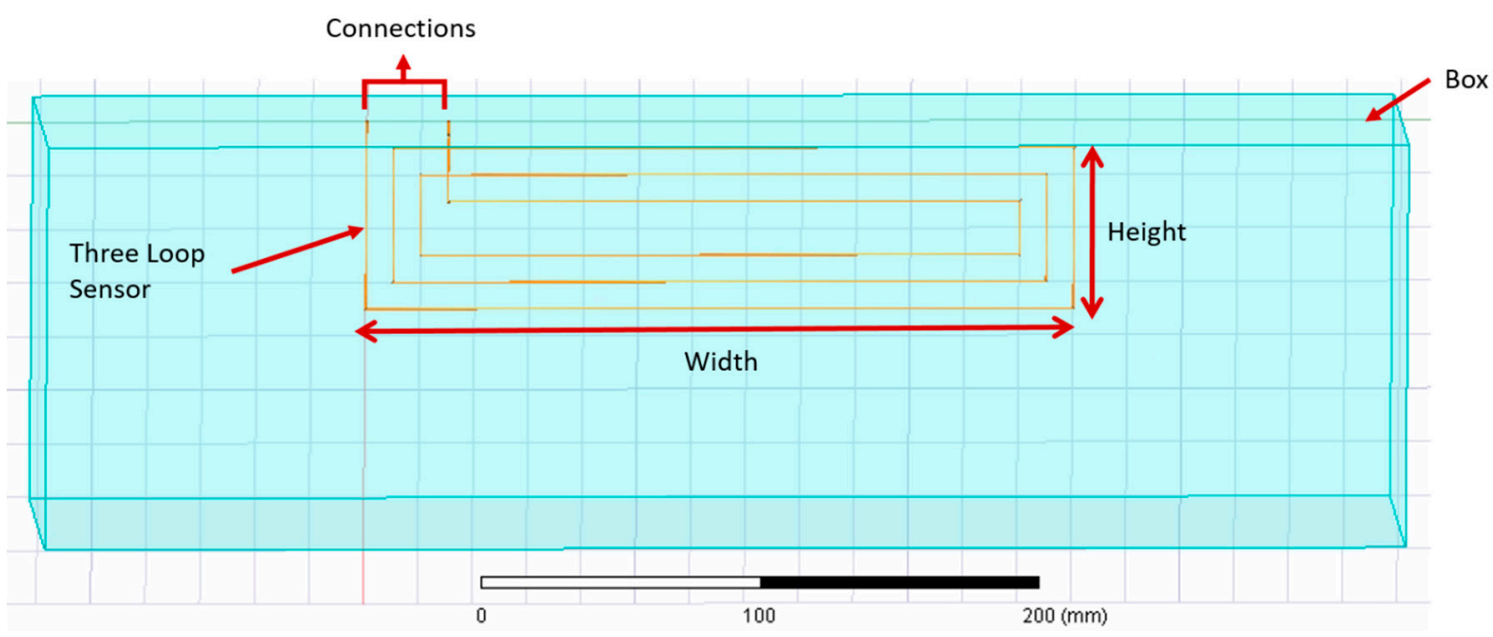

Figure 11. Flat rectangular coil with three turns simulated in Ansys.

Table 9. Inductance calculation of a single loop rectangle with a constant area $\left(15,600 \mathrm{~mm}^{2}\right)$ using Ansys simulations and Equation (1).

\begin{tabular}{ccccc}
\hline Perimeter (mm) & Width $(\mathbf{m m})$ & Height $(\mathbf{m m})$ & $\begin{array}{c}\text { Simulation } \\
\text { Inductance (nH) }\end{array}$ & $\begin{array}{c}\text { Equation (1) } \\
\text { Inductance (nH) }\end{array}$ \\
\hline 556 & 200 & 78 & 731.865 & 694.28 \\
581.82 & 220 & 70.91 & 762.972 & 721.24 \\
610 & 240 & 65 & 790.339 & 750.40 \\
640 & 260 & 60 & 832.576 & 781.16 \\
671.42 & 280 & 55.71 & 870.783 & 813.08 \\
704 & 300 & 52 & 901.676 & 845.86 \\
734.5 & 320 & 48.75 & 941.019 & 876.27 \\
\hline
\end{tabular}

Table 10. Inductance calculation of a single loop rectangle with a constant perimeter $(640 \mathrm{~mm})$ using Ansys simulations and Equation (1).

\begin{tabular}{ccccc}
\hline Area $\left(\mathbf{m m}^{\mathbf{2}}\right)$ & Width $(\mathbf{m m})$ & Height $(\mathbf{m m})$ & $\begin{array}{c}\text { Simulation } \\
\text { Inductance }(\mathbf{n H})\end{array}$ & $\begin{array}{c}\text { Equation (1) } \\
\text { Inductance }(\mathbf{n H})\end{array}$ \\
\hline 3100 & 310 & 10 & 680.557 & 574.33 \\
6000 & 300 & 20 & 757.299 & 658.86 \\
11,200 & 280 & 40 & 804.619 & 738.75 \\
15,600 & 260 & 60 & 832.576 & 781.16 \\
19,200 & 240 & 100 & 835.797 & 807.74 \\
22,000 & 220 & 120 & 847.971 & 825.16 \\
24,000 & 200 & 140 & 840.832 & 836.30 \\
25,200 & 180 & 160 & 842.452 & 842.55 \\
25,600 & 160 & & & 854.903 \\
\hline
\end{tabular}

Figures 12 and 13 illustrate the inductance behavior calculated using Equation (1) (blue curve) as well as the simulation results (orange curve), when the area isconstant, respectively. 


\section{Inductance Calculation of a Single Loop Rectangle with Constant Area $\left(15,600 \mathrm{~mm}^{2}\right)$}

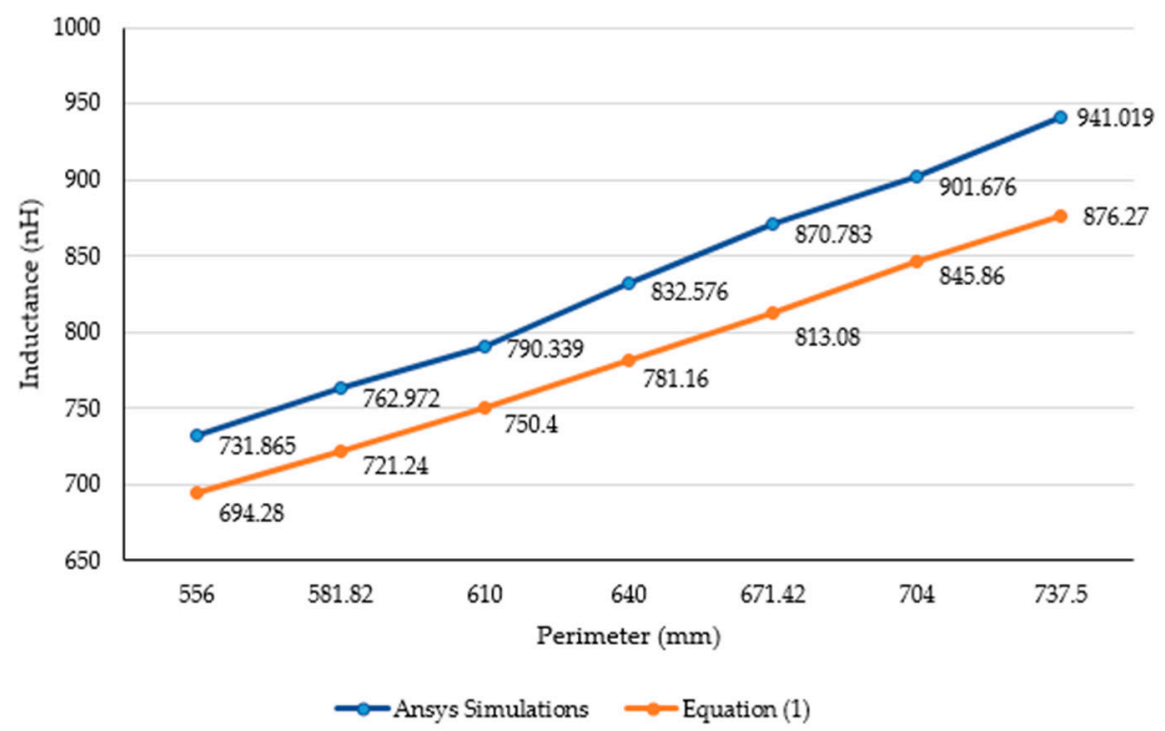

Figure 12. Theoretical and simulated inductance calculation $(\mathrm{nH})$ with a constant area $\left(15,600 \mathrm{~mm}^{2}\right)$.

\section{Inductance Calculation of a Single Loop Rectangle with Constant Perimeter $(640 \mathrm{~mm})$}

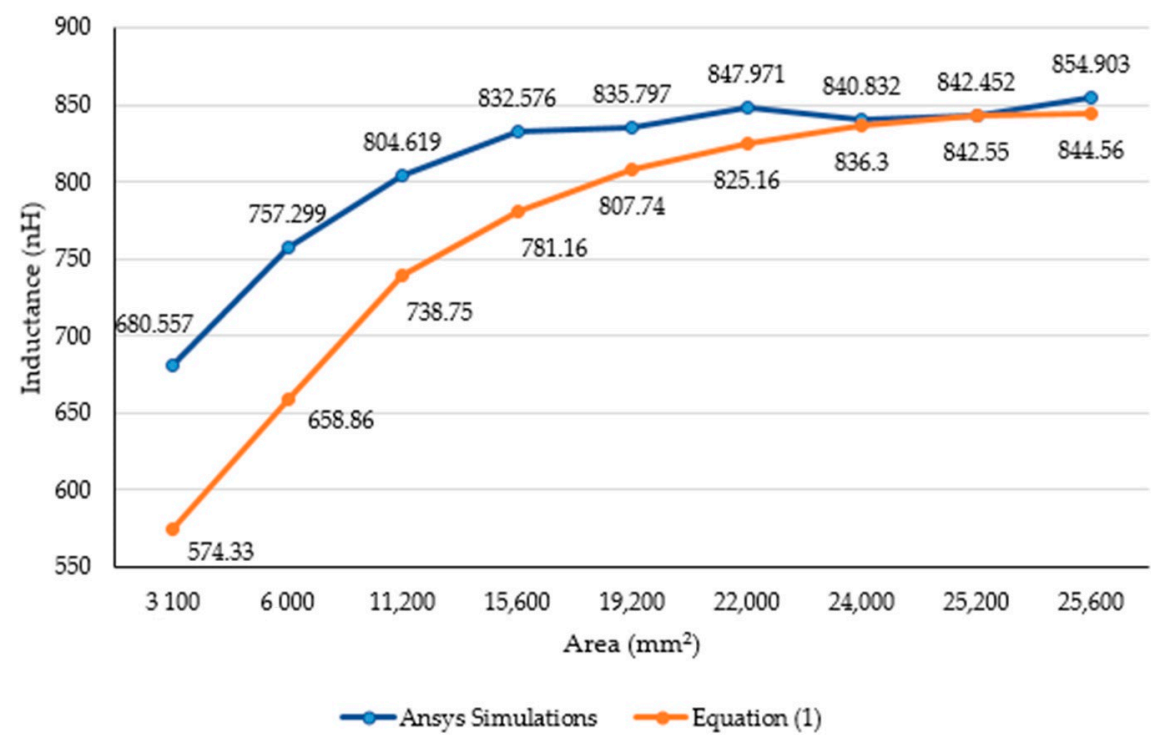

Figure 13. Theoretical and simulated inductance calculation $(\mathrm{nH})$ with a constant perimeter $(640 \mathrm{~mm})$.

Figures 14 and 15 show the comparison between simulation results and theoretical calculations. In Figure 14, the inductance values when the area was kept constant are presented. The blue dashed line is the inductance value that resulted from Equation (1) using a constant area of $15,600 \mathrm{~mm}^{2}$; while the red line is the inductance calculated using the same equation, but using the maximum dimensions of the lumbar area $\left(28,000 \mathrm{~mm}^{2}\right)$ presented in Section 3.1. Furthermore, the yellow " $x$ " represents the inductance resulting from simulations with a constant area of $15,600 \mathrm{~mm}^{2}$. The purple line is the MATLAB polynomial curve fitting (polyfit) function using a first-degree polynomial. Finally, the bold grey lines represent the maximum perimeter for the lumbar section of a healthy participant (760 mm). 


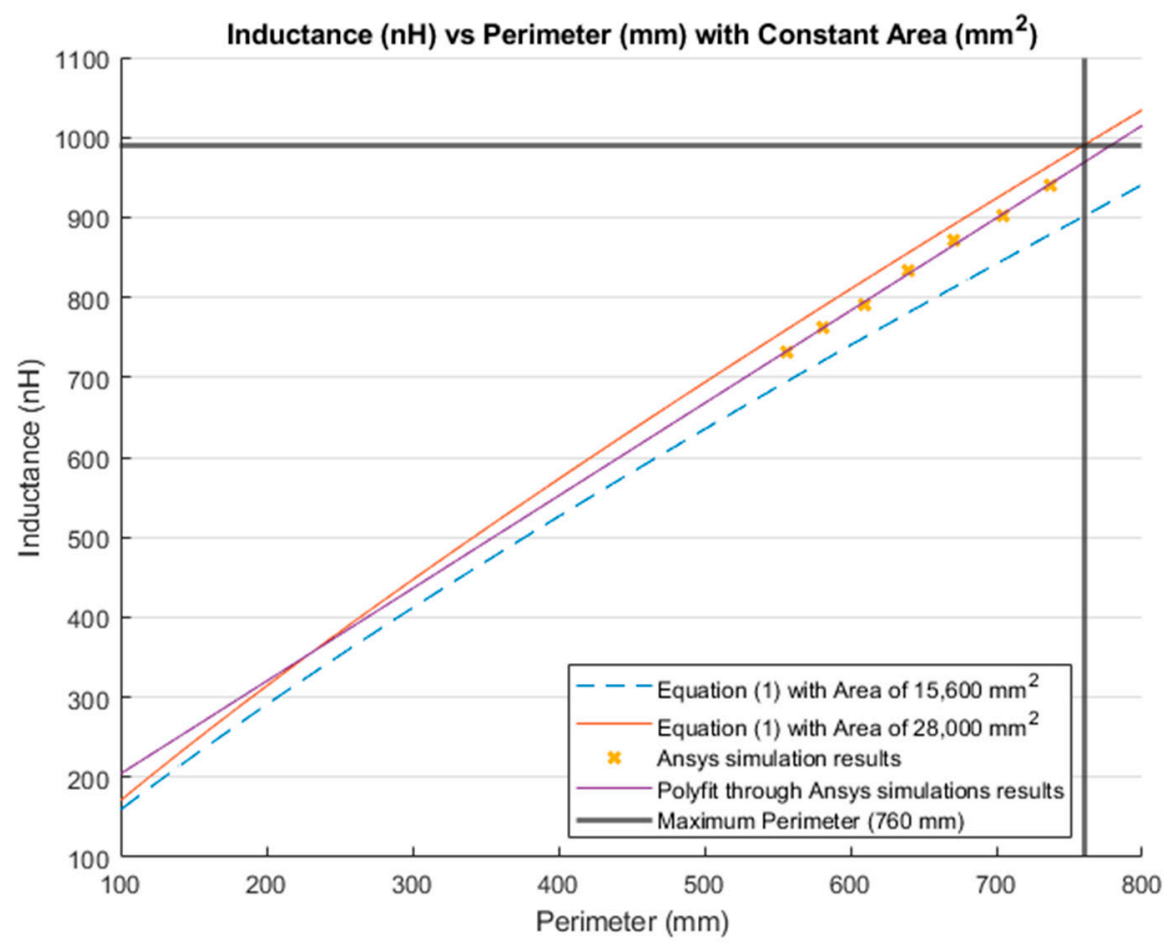

Figure 14. Comparison between the theoretical inductance calculations using Equation (1) with a constant area $\left(\mathrm{mm}^{2}\right)$ and simulations results.

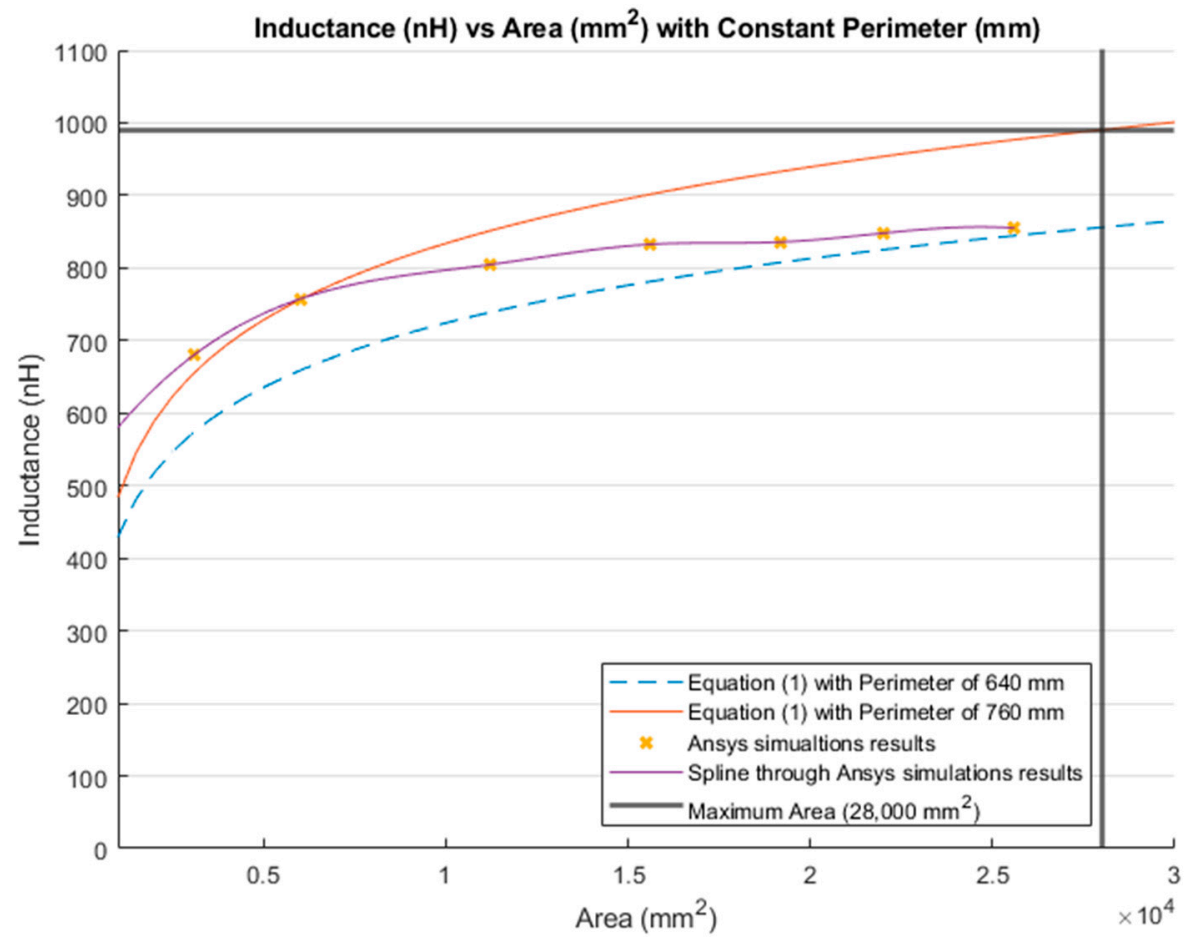

Figure 15. Comparison between theoretical inductance calculations using Equation (1) with a constant perimeter $(\mathrm{mm})$ and simulations results.

Figure 15 illustrates the inductance calculations when the perimeter was held constant. Similar to Figure 10, the blue dashed line represents the inductance calculations using Equation (1) with a constant perimeter of $640 \mathrm{~mm}$. The inductance obtained using the same equation with the maximum perimeter of the lumbar section $(760 \mathrm{~mm})$ is depicted as a red line. Moreover, the yellow " $x$ " represents the inductance obtained by the simulations 
with a constant perimeter of $640 \mathrm{~mm}$. The purple line is the MATLAB cubic spline data interpolation (spline) function that passes through the simulations results. Finally, the bold grey lines represent the maximum area $\left(28,000 \mathrm{~mm}^{2}\right)$ for the lumbar section of a healthy participant.

The inductance value corresponding to the maximum dimensions of the lumbar area of a healthy female participant $(280 \mathrm{~mm} \times 100 \mathrm{~mm})$ using Equation (1) was calculated to be $990.41 \mathrm{nH}$.

3.3.2. Comparison between Calculations and Simulations: Inductance Change Based on Height and Width

Table 11 shows the inductance results from simulations when the height was kept constant. Table 12 presents the inductance obtained from simulations when the width was held constant.

Table 11. Inductance calculation of a single loop rectangle with a constant height $(60 \mathrm{~mm})$ using Ansys simulations and Equation (2).

\begin{tabular}{ccc}
\hline Width $(\mathbf{m m})$ & Simulations Inductance (nH) & Equation (2) Inductance (nH) \\
\hline 230 & 743.565 & 670.09 \\
240 & 769.836 & 694.39 \\
250 & 795.330 & 718.70 \\
260 & 821.577 & 742.99 \\
270 & 846.542 & 767.29 \\
280 & 871.462 & 791.57 \\
290 & 896.130 & 815.86 \\
\hline
\end{tabular}

Table 12. Inductance calculation of a single loop rectangle with a constant width $(260 \mathrm{~mm})$ using Ansys simulations and Equation (2).

\begin{tabular}{ccc}
\hline Height $(\mathbf{m m})$ & Simulations Inductance $(\mathbf{n H})$ & Equation (2) Inductance (nH) \\
\hline 30 & 711.167 & 606.58 \\
40 & 752.310 & 657.07 \\
50 & 788.522 & 701.79 \\
60 & 821.577 & 742.99 \\
70 & 849.815 & 781.86 \\
80 & 874.200 & 819.08 \\
90 & 893.009 & 855.08 \\
\hline
\end{tabular}

The inductance behavior with changing the width and height is shown in Figures 16 and 17, respectively.

Figures 18 and 19 show the comparison between the results of simulations and those of Equation (2). Figure 18 illustrates the inductance values with varying the width and maintaining a constant height. The blue dashed line presents the results from Equation (2) with a constant height of $60 \mathrm{~mm}$. The red line is the inductance calculated from the same equation, but with a constant height of $100 \mathrm{~mm}$; which is the total height of the lumbar section according to the anthropometrics represented in Section 3.1. Additionally, the bold grey lines represent the maximum width for the lumbar section $(280 \mathrm{~mm})$. The yellow " $x$ " represents the inductance values simulated with a constant height of $60 \mathrm{~mm}$. Finally, the purple line is the MATLAB polynomial curve fitting (polyfit) function using a first-degree polynomial. 


\section{Inductance Calculation of a Single Loop Rectangle} with Constant Height $(60 \mathrm{~mm})$

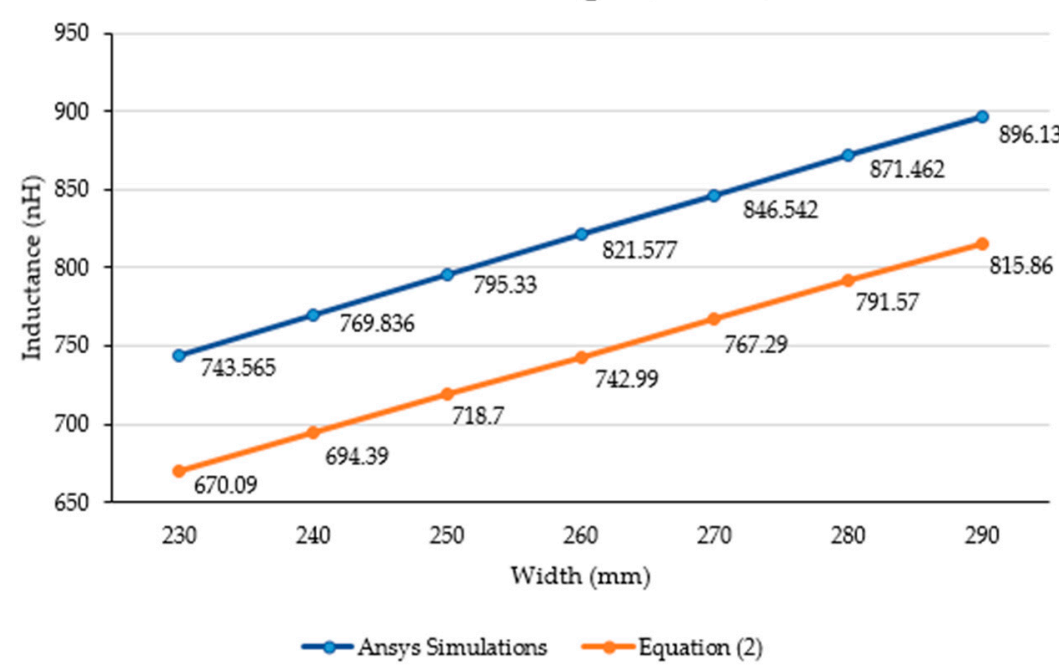

Figure 16. Inductance calculation (nH) using Equation (2) and Ansys simulations with a constant height $(60 \mathrm{~mm})$.

\section{Inductance Calculation of a Single Loop Rectangle with Constant Width $(260 \mathrm{~mm})$}

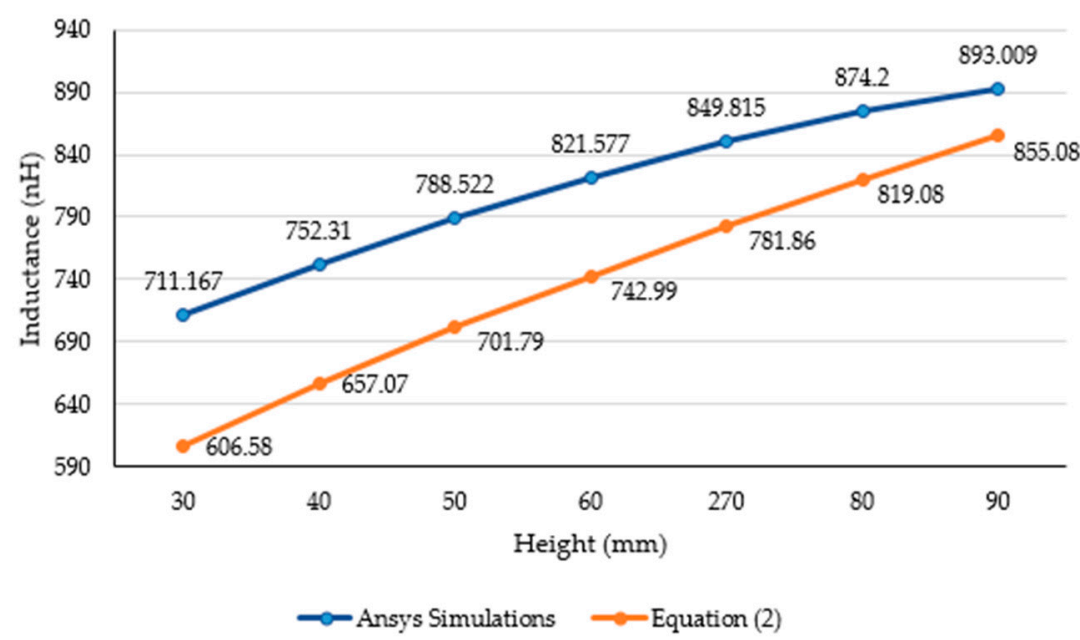

Figure 17. Inductance calculation (nH) using Equation (2) Ansys simulations with a constant width (260 mm).

Figure 19 shows the results of calculating the inductance value with a variable height and a constant width using Equation (2). The blue and red lines represent the inductance results calculated with a constant width of $260 \mathrm{~mm}$ and $280 \mathrm{~mm}$, respectively. The bold grey lines represent the maximum lumbar height $(100 \mathrm{~mm})$. The yellow " $x$ " markers represent the inductance results from the simulations run using a constant width of $260 \mathrm{~mm}$. Finally, the purple line is the MATLAB cubic spline data interpolation (spline) function based on the simulation results.

The inductance value obtained from the maximum dimensions of the lumbar section $(280 \mathrm{~mm} \times 100 \mathrm{~mm})$ using Equation (2) was $943.01 \mathrm{nH}$. 


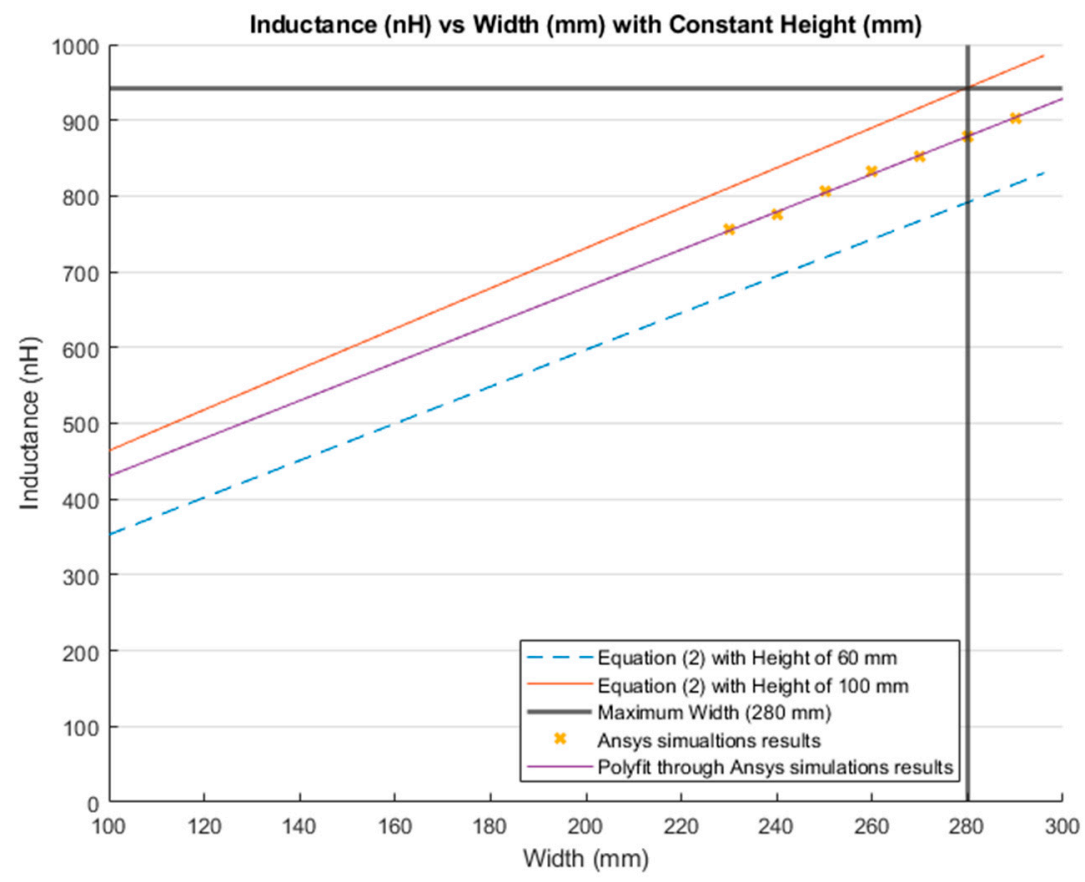

Figure 18. Comparison between theoretical inductance calculations using Equation (2) and simulations results with a constant height $(\mathrm{mm})$.

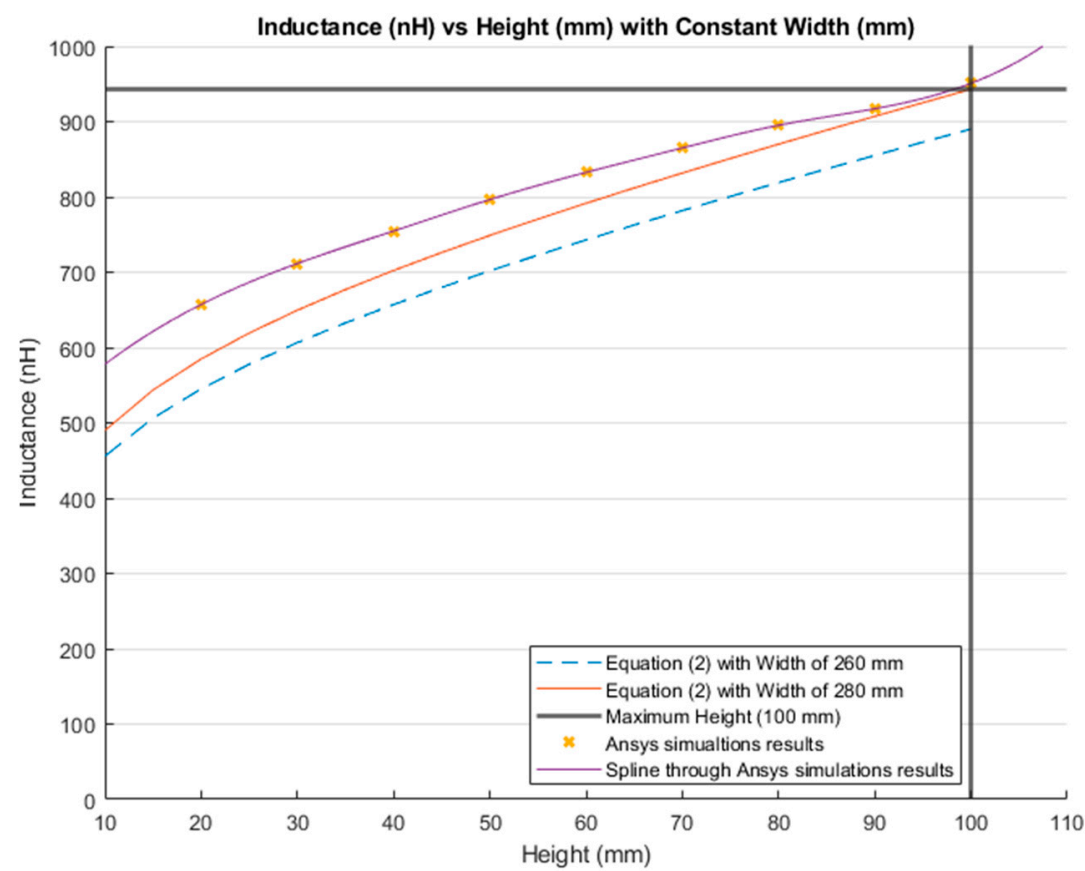

Figure 19. Comparison between the theoretical inductance calculations using Equation (2) and simulation results using a constant width $(\mathrm{mm})$.

3.3.3. Comparison between Calculations and Simulations: Inductance Change Based on the Number of Loops in a Flat Rectangular Coil

This section presents the change in the inductance value with varying the number of complete loops using Equation (3). The chosen dimensions for the flat rectangular coil were $60 \mathrm{~mm}$ height and $260 \mathrm{~mm}$ width. As mentioned in Section 3.2.3, the distance between each loop was $10 \mathrm{~mm}$. The maximum number of complete turns able to fit in the rectangle with the aforementioned dimensions was 3. The MATLAB cubic spline data interpolation (spline) function was used to interpolate the behavior of the results. 
Figure 20 illustrates the comparison between the theoretical results from Equation (3) and simulations in which results of Equation (3) results are denoted with a blue " $\mathrm{o}$ " markers and simulations results are marked with orange " $x$ " markers. The MATLAB cubic spline data interpolation (spline) function was used to extrapolate the values and generate the corresponding curve for each case.

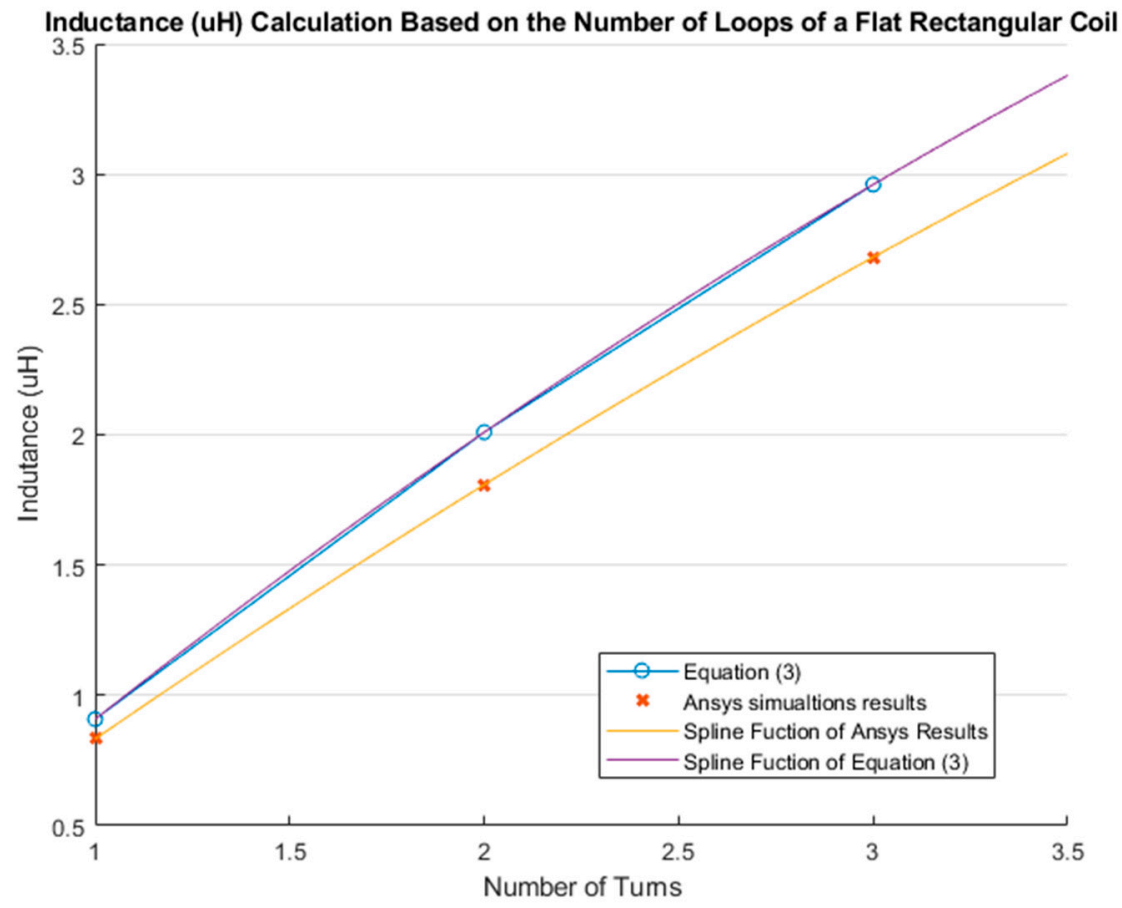

Figure 20. Comparison between the results obtained from Equation (3) and simulations.

\section{Discussion}

The inductance of a single loop rectangle was calculated using two different equations. Figure 2 shows the results of Equation (1), which describes the inductance based on the perimeter and the area. Equation (1) demonstrated an almost linear behavior when the area was kept constant. However, in the case of a constant perimeter, the inductance behavior was similar to that of a logarithmic graph. Equation (2), which relates the inductance value to the height and width of the rectangle (Figure 3), described the inductance with a linear behavior when the height was constant. On the other hand, when the width was constant, the inductance showed a linear behavior when the height was approximately $25 \mathrm{~mm}$. Unfortunately, these two equations led to different results for the inductance of a single loop rectangle, such that there was a difference of approximately $40 \mathrm{nH}$ between the inductance values calculated using these equations for the same sensor dimensions. This discrepancy in calculated values increased as the rectangle became bigger. An example of this discrepancy can be seen using the lumbar anthropometric dimensions of a healthy participant from Section 3.1, where the rectangle had a width of $280 \mathrm{~mm}$ and a height of $100 \mathrm{~mm}$. Using Equation (1), the inductance value was calculated to be $990.42 \mathrm{nH}$, while using Equation (2), the inductance was equal to $943.01 \mathrm{nH}$. The difference between these results was $47.41 \mathrm{nH}$. The equations used in this chapter are solely based on the geometry of the rectangle loop and entirely neglect the material from which the rectangle loop is made.

Finally, when the inductance was studied based on the height and width rather than the area and perimeter, it was possible to observe a more linear behavior, which facilitates the theoretical prediction of the inductance when using a rectangular shape. The inductance calculation based on the area and perimeter reported had closer results to the simulations compared to the results based on width and height. The average difference between the simulation results and Equation (1) calculations was $49.849 \mathrm{nH}$ and $43.066 \mathrm{nH}$ for constant area and constant perimeter, respectively. The average difference between the simulation 
results and Equation (2) calculations was $77.650 \mathrm{nH}$ and $75.164 \mathrm{nH}$ for a constant height and width, respectively. Additionally, the simulated inductance value using the lumbar anthropometric dimensions was $1.003 \mu \mathrm{H}$. The difference between this simulation and the results from Equations (1) and (2) using the same lumbar dimensions was $12.58 \mathrm{nH}$ and $59.99 \mathrm{nH}$, respectively.

In general, the behavior and trend of inductance values were similar in both simulations and theoretical calculations, but the obtained inductance values were different. Nonetheless, the simulations were closer to the results of Equation (1) than to those of Equation (2). All simulations resulted in a higher inductance compared to theoretical calculations. This outcome could be a result of considering the material of the rectangle loop and the environment surrounding the rectangle loop while running the simulations. Future investigation should include an analysis on the change of the inductance value when a biological body is in close proximity to the inductive textile sensor. Furthermore, unlike studies such as $[4,5]$, the equations presented in this study do not consider mutualinductance or self-inductance. However, inserting these parameters into the calculations increased the complexity.

The dimensions of the inductive textile sensor were chosen based on using the anthropometric dimensions of the lumbar area of a healthy participant and according to the inductance behavior. A rectangle of smaller dimensions (260 mm width and $60 \mathrm{~mm}$ height) was arbitrary selected to compare the inductance value against the maximum inductance for the lumbar section of the back. Based on Equation (1), this smaller rectangle covered up to $78.81 \%$ of the maximum inductance range. While using Equation (2), the same smaller rectangle covered up to $78.79 \%$. The maximum inductance was obtained by using the dimensions of the entire lumbar section of a healthy participant, and is presented in Section 3.1.

Figures 21 and 22 show the covered area based on Equation (1). Moreover, Figures 23 and 24 illustrate the covered area based on Equation (2). In both cases, the covered inductance change is highlighted in grey and the black " $x$ " represents the simulation results for a rectangle with dimensions $260 \mathrm{~mm} \times 60 \mathrm{~mm}$.

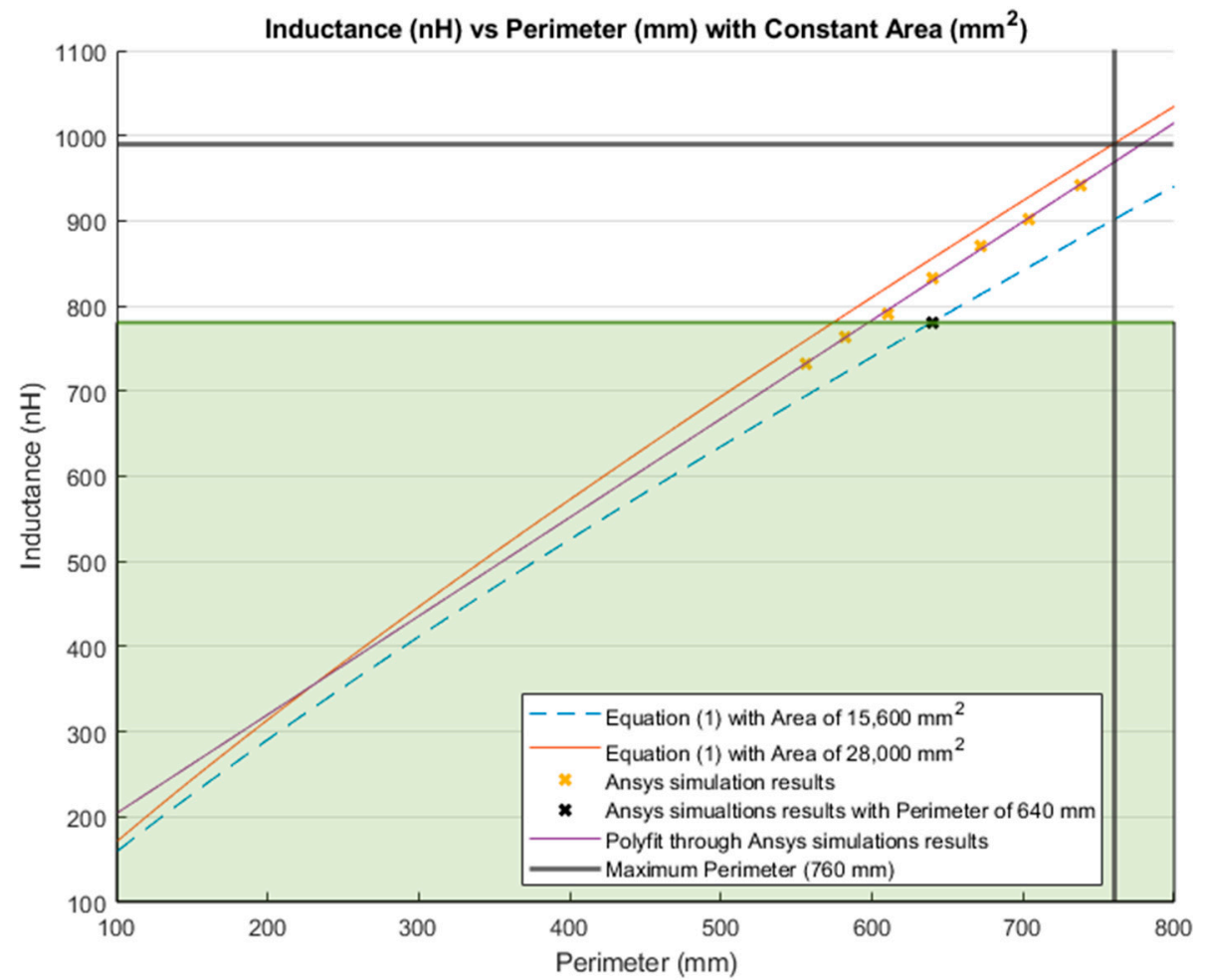

Figure 21. Inductance calculation with a constant area $\left(\mathrm{mm}^{2}\right)$ and a variable perimeter $(\mathrm{mm})$. Highlighted in green shading is $78.81 \%$ of the total inductance change. 


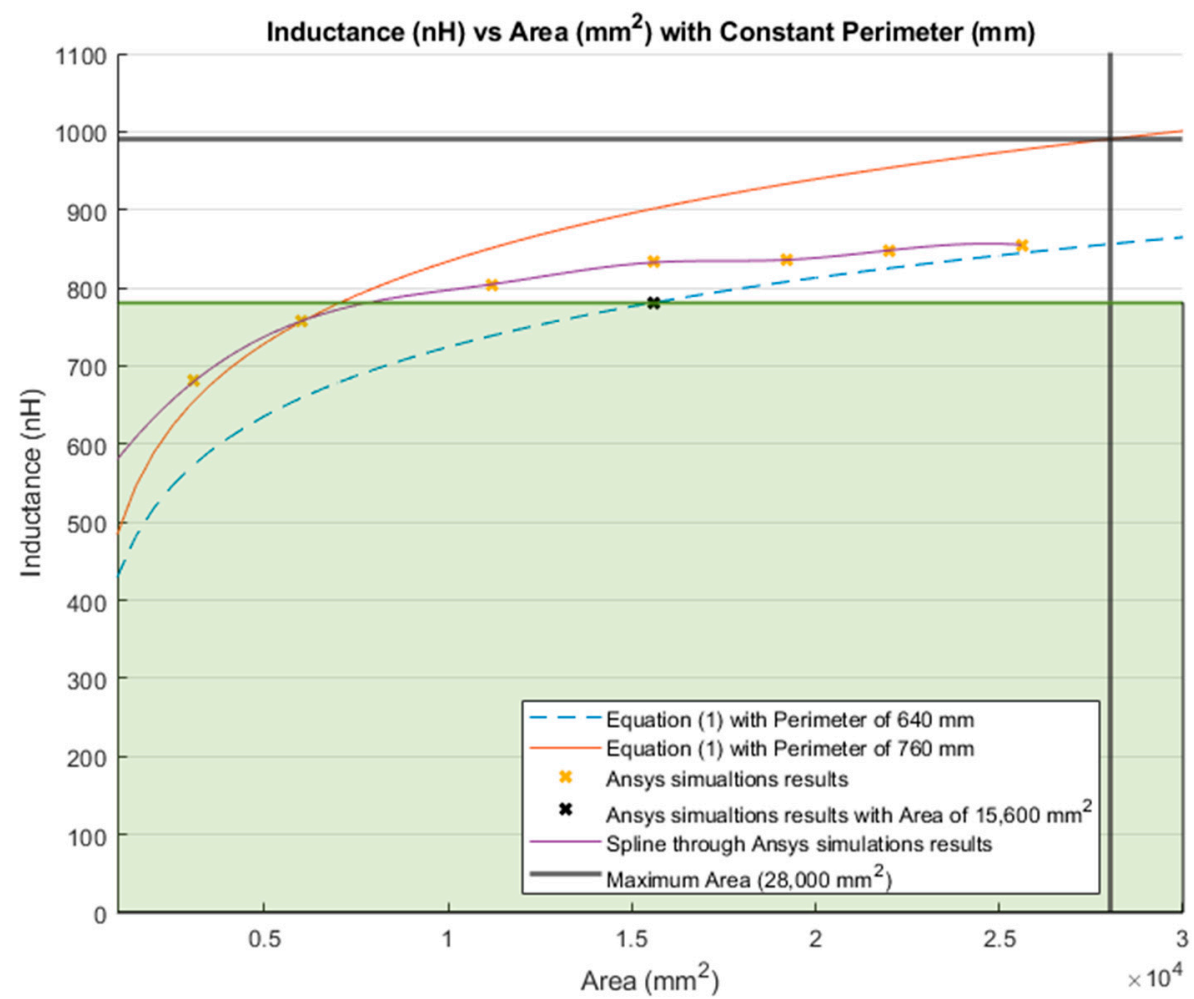

Figure 22. Inductance calculation with a constant perimeter $(\mathrm{mm})$ and a variable area $\left(\mathrm{mm}^{2}\right)$. Highlighted in green shading is $78.81 \%$ of the total inductance change.

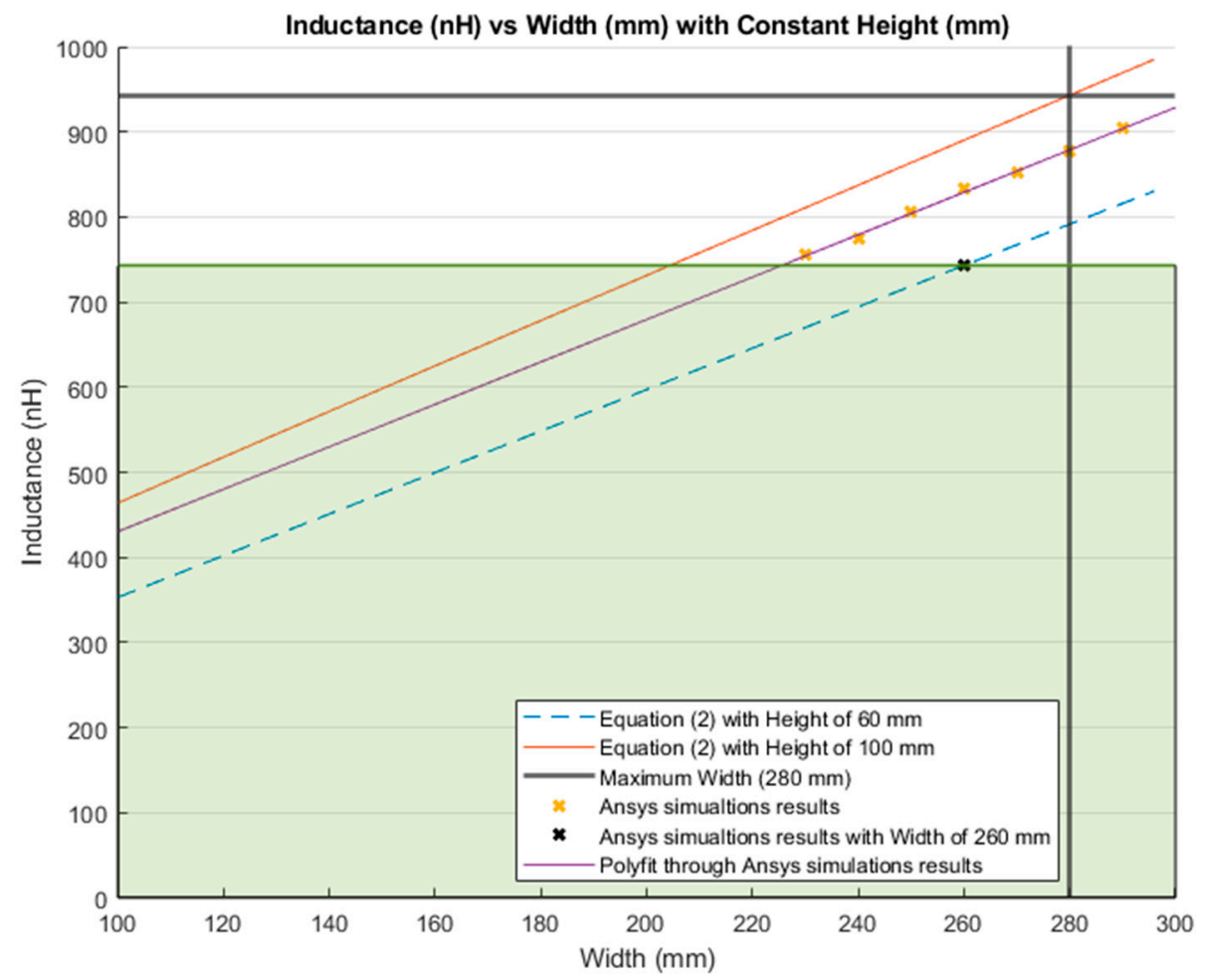

Figure 23. Inductance calculation with a constant height $(\mathrm{mm})$ and a variable width $(\mathrm{mm})$. Highlighted in green shading is $78.79 \%$ of the total inductance change. 


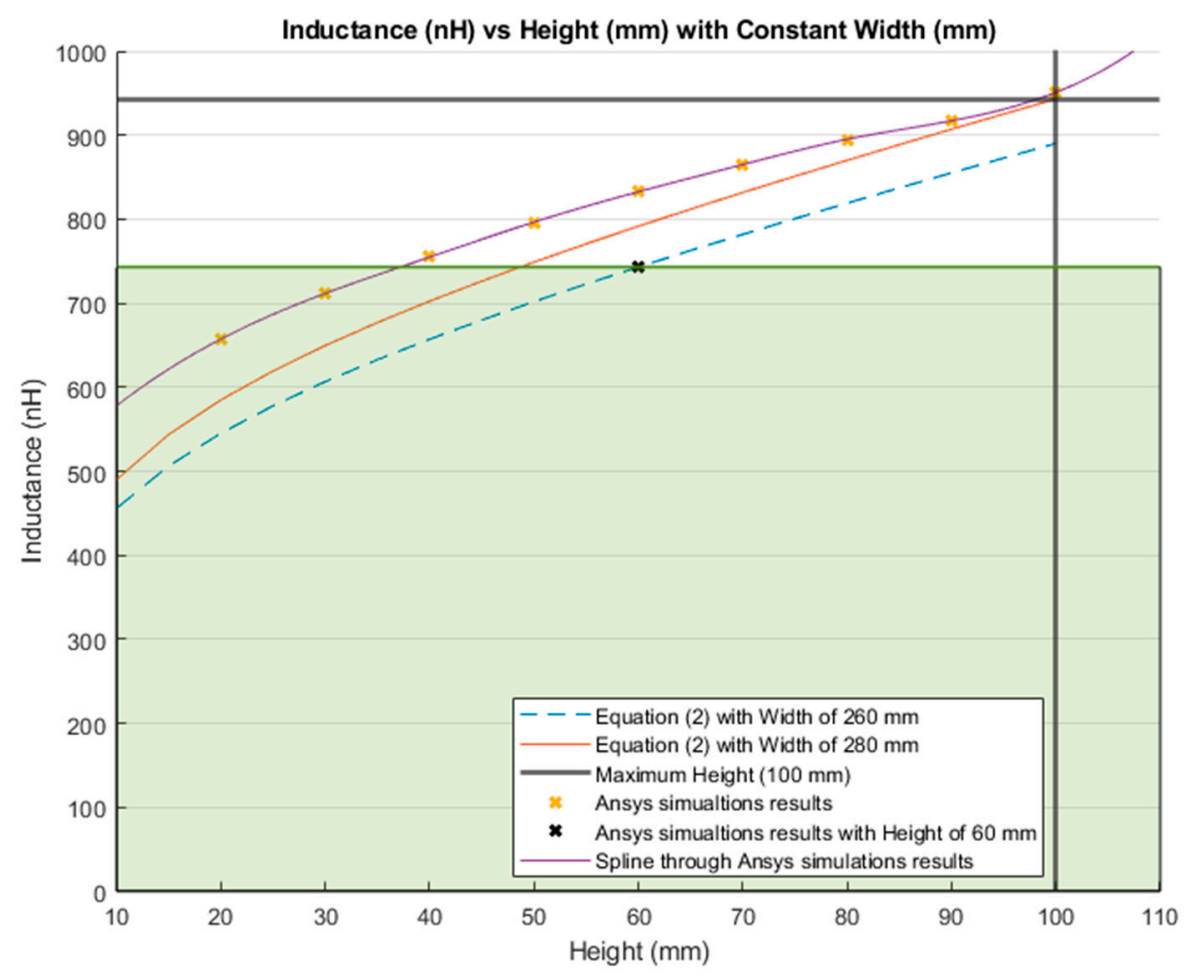

Figure 24. Inductance calculation with a constant width $(\mathrm{mm})$ and a variable height $(\mathrm{mm})$. Highlighted in green shading is $78.79 \%$ of the total inductance change.

Results of Equation (3) were also different from those of the simulations. The difference between the inductance value calculated with Equation (3) and the simulated one increased with the number of loops. More specifically, the inductance value for a single loop was calculated to be $0.909 \mu \mathrm{H}$ using Equation (3), while simulations yielded an inductance value of $0.833 \mu \mathrm{H}$ for the same case, resulting in a difference of $0.0759 \mu \mathrm{H}$ between the two methods. When considering three loops, the difference in the inductance value increased to $0.279 \mu \mathrm{H}$, which was more than twice that obtained for a single loop. Nonetheless, the behavior and trend of inductance were similar in both methods, as shown in Figure 16.

The percentage reduction of the size and inductance value from the total lumbar dimensions to the arbitrary chosen dimension $(260 \mathrm{~mm}$ width and $60 \mathrm{~mm}$ height) were as follows; the area was reduced to $44.29 \%$, the perimeter was reduced to $15.79 \%$, the height was reduced to $66.67 \%$, and finally the width was reduced to $7.14 \%$. These size modifications resulted in a reduction of the inductance by $21.19 \%$ and $21.21 \%$ for Equations (1) and (2), respectively. Reducing the perimeter and width has a greater impact on the inductance value than on the area and the height. As shown in Figures 22 and 24, the inductance behavior, when modifying the area and height, followed the pattern of a logarithm. Therefore, when deciding the size of the sensor, it was better to modify the area or height to avoid a drastic decrease on its inductance. Additionally, increasing the number of complete loops without modifying the area increased the inductance value.

The theoretical inductance value of a flat rectangular coil of $260 \mathrm{~mm}$ width and $60 \mathrm{~mm}$ height with three complete loops using Equation (3) was $2.960 \mu \mathrm{H}$, while the simulated inductance value was $2.681 \mu \mathrm{H}$. The inductance value difference between the simulation and Equation (3) was $0.279 \mu \mathrm{H}$. The fabricated inductive strain textile sensor presented in our previous study had a value of $4.500 \mu \mathrm{H}$ [3]. However, this inductive strain textile sensor was made with a zigzag pattern and included a connection line along the spine. As discussed in Section 2.4: Zigzag properties, use of a zigzag pattern increases the inductance value by $35 \%$. Therefore, the inductance value after increasing the simulated value $(2.681 \mu \mathrm{H})$ by $35 \%$ was $3.619 \mu \mathrm{H}$. The difference between the simulation result and the fabricated sensor presented in [3] was $24.309 \%$. This difference was due to the connection 
line not considered in this study and small differences between the simulation and actual parameters, since the inductive textile sensor was manufactured by hand. Moreover, a simulation presented in our previous study [1], where a simulation of the inductive strain textile sensor included the zigzag pattern and the connection line obtained an inductance value of $4.698 \mu \mathrm{H}$. The difference in inductance value between this last simulation and the manufactured inductive textile sensor was $4.4 \%$.

A rectangle of $260 \mathrm{~mm}$ width and $60 \mathrm{~mm}$ height proved to cover up to $78.8 \%$ of the maximum possible inductance value in both Equations (1) and (2), and consequently, was suggested to be an optimal option when the size of the inductive textile sensor was chosen. Additionally, the maximum number of loops that could be fitted into the aforementioned dimensions was three. Considering that the sensor was made of non-stretchable material, increasing the number of loops inevitably increased the stiffness of the fabric, which could interfere with the comfort for the user. Among the important requirements for wearable devices are comfort and being as unobstructive as possible, so users can perform their regular activities as normally as possible $[1,6,8,9]$.

\section{Conclusions}

A design process for an inductive sensor with a flat rectangular coil configuration was presented in this study. The design process was then evaluated by presenting an example case, where the inductive sensor was design to monitor forward bending movements.

The results of the inductive strain textile sensor design and validation presented in this study showed a similar behavior and trend of inductance values in theoretical calculations and simulations, but the obtained values were different. Equation (1) was reported to have closer inductance results to the simulations than Equation (2). The inductance value has a linear behavior using Equations (1) and (2), when the area and height are kept constant, respectively. An inductive sensor of $260 \mathrm{~mm}$ width and $60 \mathrm{~mm}$ height covered up to $78.8 \%$ of the maximum possible inductance value for both equations. The maximum number of loops capable of fit into the aforementioned dimensions was three. Therefore, we considered that the optimal size of the inductive strain textile sensor was a flat rectangle coil of $260 \mathrm{~mm}$ width and $60 \mathrm{~mm}$ height with three complete loops.

Author Contributions: Conceptualization, A.G.P. and C.M.; methodology A.G.P.; simulations A.G.P.; formal analysis, A.G.P.; writing-original draft preparation A.G.P.; writing-review and editing, A.G.P. and C.M.; supervision, C.M.; funding acquisition, C.M. All authors have read and agreed to the published version of the manuscript.

Funding: This research was funded by the Canadian Institutes of Health Research (CIHR), Natural Sciences and Engineering Research Council of Canada (NSERC), and Canada Research Chair (CRC) programs.

Institutional Review Board Statement: The ethics of this study was approved by the Office of Research Ethics at Simon Fraser University (protocol code 2018s0265 and 25 September 2020 of approval).

Informed Consent Statement: Informed consent was obtained from all subjects involved in the study. Data Availability Statement: Data sharing not applicable.

Conflicts of Interest: The authors declare no conflict of interest.

\section{References}

1. Mokhlespour Esfahani, M.I.; Zobeiri, O.; Moshiri, B.; Narimani, R.; Mehravar, M.; Rashedi, E.; Parnianpour, M. Trunk motion system (TMS) using printed body worn sensor (BWS) via data fusion approach. Sensors 2017, 17, 112. [CrossRef] [PubMed]

2. Atalay, O. Textile-Based, Interdigital, Capacitive, Soft-Strain Sensor for Wearable Applications. Materials 2018, 11, 765. [CrossRef] [PubMed]

3. Patiño, A.G.; Khoshnam, M.; Menon, C. Wearable device to monitor back movements using an inductive textile sensor. Sensors 2020, 20, 5-8.

4. Fava, J.O.; Lanzani, L.; Ruch, M.C. Multilayer planar rectangular coils for eddy current testing: Design considerations. NDT E Int. 2009, 42, 713-720. [CrossRef] 
5. Martinot-Lagarde, P.; Sartene, R.; Mathieu, M.; Durand, G. What does inductance plethysmography really measure? J. Appl. Physiol. 1988, 64, 1749-1756. [CrossRef] [PubMed]

6. Catrysse, M.; Puers, R.; Hertleer, C.; van Langenhove, L.; van Egmond, H.; Matthys, D. Towards the integration of textile sensors in a wireless monitoring suit. Sens. Actuators A Phys. 2004, 114, 302-311. [CrossRef]

7. Zhong, J.; Member, S.; Kiourti, A.; Sebastian, T. Conformal Load-Bearing Spiral Antenna on Conductive Textile Threads. IEEE Antennas Wirel. Propag. Lett. 2016, 16, 230-233. [CrossRef]

8. Dionisi, A.; Marioli, D.; Sardini, E.; Serpelloni, M. Autonomous Wearable System for Vital Signs Measurement With EnergyHarvesting Module. IEEE Trans. Instrum. Meas. 2016, 65, 1423-1434. [CrossRef]

9. Yoo, H.J. Your heart on your sleeve: Advances in textile-based electronics are weaving computers right into the clothes we wear. IEEE Solid-State Circuits Mag. 2013, 5, 59-70.

10. Coosemans, J.; Hermans, B.; Puers, R. Integrating wireless ECG monitoring in textiles. Sens. Actuators A Phys. 2006, 130-131, 48-53. [CrossRef]

11. Koo, H.R.; Lee, Y.J.; Gi, S.; Khang, S.; Lee, J.H.; Lee, J.H.; Lim, M.G.; Park, H.J.; Lee, J.W. The effect of textile-based inductive coil sensor positions for heart rate monitoring. J. Med. Syst. 2014, 38, 2. [CrossRef] [PubMed]

12. Wijesiriwardana, R. Inductive fiber-meshed strain and displacement transducers for respiratory measuring systems and motion capturing systems. IEEE Sens. J. 2006, 6, 571-579. [CrossRef]

13. Wu, D.; Wang, L.; Zhang, Y.T.; Huang, B.Y.; Wang, B.; Lin, S.J.; Xu, X.W. A wearable respiration monitoring system based on digital respiratory inductive plethysmography. In Proceedings of the 2009 Annual International Conference of the IEEE Engineering in Medicine and Biology Society, Minneapolis, MN, USA, 3-6 September 2009; pp. 4844-4847.

14. Gonçalves, C.; da Silva, A.F.; Gomes, J.; Simoes, R. Wearable E-Textile Technologies: A Review on Sensors, Actuators and Control Elements. Inventions 2018, 3, 14. [CrossRef]

15. Bonroy, B.; Meijer, K.; Dunias, P.; Cuppens, K.; Gransier, R.; Vanrumste, B. Ambulatory Monitoring of Physical Activity Based on Knee Flexion/Extension Measured by Inductive Sensor Technology. ISRN Biomed. Eng. 2013, 2013, 1-10. [CrossRef]

16. Pheasant, S. Bodyspace Anthropometry, Ergonomics and the Design of Work, 2nd ed.; Taylor \& Francis: London, UK, 2003 ; Volume 1.

17. Thompson, M.T. Inductance Calculation Techniques-Part II: Approximations and Handbook Methods. Power Control Intell. Motion 1999, 11.

18. Terman, F.E. Radio Engineers' Handbook, 1st ed.; McGraq-Hill Book Company Inc.: New York, NY, USA, 1943.

19. Grover, F.W. Methods, formulas, and tables for the calculation of antenna capacity. Sci. Pap. Bur. Stand. 1926, 22, 569. [CrossRef]

20. Sardini, E.; Serpelloni, M.; Ometto, M. Smart vest for posture monitoring in rehabilitation exercises. In Proceedings of the 2012 IEEE Sensors Applications Symposium Proceedings, Brescia, Italy, 7-9 February 2012; pp. 161-165.

21. Tavassolian, M.; Cuthbert, T.J.; Napier, C.; Peng, J.; Menon, C. Textile-Based Inductive Soft Strain Sensors for Fast Frequency Movement and Their Application in Wearable Devices Measuring Multiaxial Hip Joint Angles during Running. Adv. Intell. Syst. 2020, 2, 1900165. [CrossRef]

22. Atalay, O.; Tuncay, A.; Husain, M.D.; Kennon, W.R. Comparative study of the weft-knitted strain sensors. J. Ind. Text. 2017, 46, 1212-1240. [CrossRef]

23. Atalay, O.; Kennon, W.R.; Dawood, M. Husain Textile-based weft knitted strain sensors: Effect of fabric parameters on sensor properties. Sensors 2013, 13, 11114-11127. [CrossRef]

24. Vogl, A.; Parzer, P.; Babic, T.; Leong, J.; Olwal, A.; Haller, M. StretchEBand: Enabling Fabric-Based Interactions through Rapid Fabrication of Textile Stretch Sensors. In Proceedings of the CHI 2017 (SIGCHI Conference on Human Factors in Computing Systems), Denver, CO, USA, 6-11 May 2017; pp. 2617-2627.

25. Paradiso, R.; Loriga, G.; Taccini, N. A wearable health care system based on knitted. IEEE Trans. Inf. Technol. Biomed. 2005, 9 , 337-344. [CrossRef]

26. Mattmann, C. Body Posture Detection Using Strain Sensitive Clothing; ETH: Zurich, Switzerland, 2008.

27. Bjørk, I.T.; Samdal, G.B.; Hansen, B.S.; Tørstad, S.; Hamilton, G.A. Job satisfaction in a Norwegian population of nurses: A questionnaire survey. Int. J. Nurs. Stud. 2007, 44, 747-757. [CrossRef] [PubMed]

28. Castel, E.S.; Ginsburg, L.R.; Zaheer, S.; Tamim, H. Understanding nurses' and physicians' fear of repercussions for reporting errors: Clinician characteristics, organization demographics, or leadership factors? BMC Health Serv. Res. 2015, 15, 1-10. [CrossRef] [PubMed]

29. Ang, S.Y.; Dhaliwal, S.S.; Ayre, T.C.; Uthaman, T.; Fong, K.Y.; Tien, C.E.; Zhou, H.; Della, P. Demographics and Personality Factors Associated with Burnout among Nurses in a Singapore Tertiary Hospital. BioMed Res. Int. 2016, 2016. [CrossRef] [PubMed]

30. Churchill, E.; Laubach, L.L.; Mcconville, J.T.; Tebbetts, I. Anthropometric Source Book. Volume 1: Anthropometry for Designers. Available online: https://msis.jsc.nasa.gov/sections/section03.htm\#_3.3_ANTHROPOMETRIC_AND. (accessed on 18 June 2020).

31. Wang, M.; Leger, A.B.; Dumas, G.A. Prediction of back strength using anthropometric and strength measurements in healthy females. Clin. Biomech. 2005, 20, 685-692. [CrossRef] [PubMed]

32. Marras, W.S.; Jorgensen, M.J.; Granata, K.P.; Wiand, B. Female and male trunk geometry: Size and prediction of the spine loading trunk muscles derived from MRI. Clin. Biomech. 2001, 16, 38-46. [CrossRef]

33. Podbevšek, T. For a good fitted skirt, the waist-to-hip distance should be measured. Anthropol. Notebooks 2014, $20,77-88$. 
34. FreeSVG.org. Human Male and Female Body Line Art. Available online: https://freesvg.org/1549491622 (accessed on 14 August 2020).

35. Wikimedia Commons. Columna Vertebras.jpg. Available online: https://commons.wikimedia.org/wiki/File:Columna_vertebras. jpg (accessed on 14 August 2020).

36. Wikimedia Commons. Human body silhouette.svg. Available online: https://commons.wikimedia.org/wiki/File:Human_ body_silhouette.svg (accessed on 14 August 2020). 